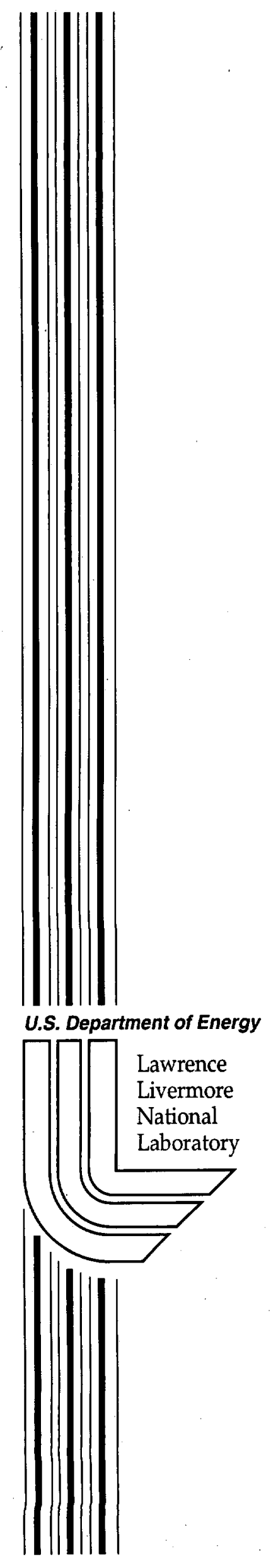

UCRL-ID-145662-REV-1 ${ }^{*}$

\title{
Tank Leak Experiment at the Mock Tank Site, 200 East Area: Electrical Resistance Tomography- Preliminary Results
}

\author{
A.L. Ramirez, W.D. Daily, A. Binley
}

January 18, 2002 


\section{DISCLAIMER}

This document was prepared as an account of work sponsored by an agency of the United States Government. Neither the United States Government nor the University of California nor any of their employees, makes any warranty, express or implied, or assumes any legal liability or responsibility for the accuracy, completeness, or usefulness of any information, apparatus, product, or process disclosed, or represents that its use would not infringe privately owned rights. Reference herein to any specific commercial product, process, or service by trade name, trademark, manufacturer, or otherwise, does not necessarily constitute or imply its endorsement, recommendation, or favoring by the United States Government or the University of California. The views and opinions of authors expressed herein do not necessarily state or reflect those of the United States Government or the University of California, and shall not be used for advertising or product endorsement purposes.

This work was performed under the auspices of the U.S. Department of Energy by the University of California, Lawrence Livermore National Laboratory under Contract No. W-7405-Eng-48.

This report has been reproduced directly from the best available copy.

Available electronically at http://www.doe.gov/bridge

Available for a processing fee to U.S. Department of Energy

and its contractors in paper from

U.S. Department of Energy

Office of Scientific and Technical Information

P.O. Box 62

Oak Ridge, TN 37831-0062

Telephone: (865) 576-8401

Facsimile: (865) 576-5728

E-mail: reports@adonis.osti.gov

Available for the sale to the public from

U.S. Department of Commerce

National Technical Information Service

5285 Port Royal Road

Springfield, VA 22161

Telephone: (800) 553-6847

Facsimile: (703) 605-6900

E-mail: orders@ntis.fedworld.gov

Online ordering: http://www.ntis.gov/ordering.htm

OR

Lawrence Livermore National Laboratory

Technical Information Department's Digital Library ।

http://www.llnl.gov/tid/Library.html 


\title{
Tank Leak Experiment at the Mock Tank Site, 200 East Area: \\ Electrical Resistance Tomography-Preliminary Results
}

\author{
Submitted by \\ Lawrence Livermore National Laboratory \\ Livermore, Ca 94550 \\ Abelardo L. Ramirez, William D. Daily and Andrew Binley* \\ [ [*Lancaster University, Lancaster, UK]
}

January 18,2002

Summary

Electrical resistance measurements were used to monitor several releases of brine from the Mock Tank Test site at the 200 East Area. Three different methods were used to analyze the data: 1) a simple average of the raw data was used as an indicator of the presencelabsence of a leak, 2) tomography of the region beneath the tank using data from steel-cased borehole, and 3) tomography of the region beneath the tank using data from vertical electrode arrays. Each of these methods was able to detect the presence of what appeared to be conductive plumes forming beneath the tank. The results suggest the following: 1) The minimum detectable leak volume is of the order of a few hundred gallons. 2) A procedure involving the use of reciprocal data can be used to evaluate the reliability of the results and minimize the potential for false-positive and false-negative conclusions. 3) The dry wells may be used as long electrodes to obtain $2 D$ images of the plume under the tank. 4) $3 D$ electrical resistance tomography (ERT) images provide information that can be used to determine the released volume, the speed and direction of plume movement, the regions of the soil that are being contaminated, and the approximate location of the hole in the tank. 5) It may be possible to map pre-existing plumes when no pre-spill data exists. 6) A "quick. look" calculation can be used in the field can reliably detect the occurrence of a leak.

Work performed under the auspices of the U.S. Department of Energy by the Lawrence Livermore National Laboratory under Contract W-7405-Eng-48. 


\section{Introduction}

This report covers the electrical resistance tomography (ERT) work performed at the Mock Tank site, 200 East Area, Hanford Reservation, during the months of July and August, 2001. The work reported herein is to be considered preliminary because it is work in progress. Some of the analyses and interpretation of results are incomplete at this time.

The goals of the ERT work were to:

1- determine if there was a simple, non imaging electrical measurement, which could detect the presence of a leak of fluid from a single shell tank.

2- determine if electrical measurements could be made using dry wells (steel cased boreholes) to detect the presence of a leak and make a rough determination of its magnitude and location.

3- determine if electrical measurements could be made using ERT electrode arrays installed around a tank to detect a leak and image the resulting plume in order to estimate its origin, size and movement.

Electrical resistance tomography (ERT) is a method that calculates subsurface images of electrical properties from a large number of impedance measurements. Arrays of electrodes are placed on or beneath the surface. A low frequency (typically 0.125 to 1.0 $\mathrm{Hz}$ ) current is driven between two electrodes. As this current flows through the ground, it establishes voltages at the other electrodes that are measured and recorded. Two other electrodes are then used to drive current, and voltages are again measured on all other electrodes. This process is repeated until all linearly independent combinations of current 
and voltage measurements are made. For 30 electrodes, there are 405 such measurements ( $n[n-3] / 2$ where $n$ is the number of electrodes). Based on our field experience, we suggest that measurement errors are best determined by a reciprocity test. Two measurements are reciprocal when the transmitter dipole and the receiver dipole are interchanged. The ratio of voltage to current for both the normal and reciprocal measurements will be identical if the process is linear (i.e., obey Ohm's law) and there are no measurement errors.

The raw data are inverted to produce tomographic images of electrical properties in the ground. For the simple case where the impedance is adequately described by the resistance, the method is called electrical resistance tomography (ERT). In this case, there are no phase differences (between the current and voltage). ERT data has been described by Daily and Owen (1991), Oldenburg and Li (1994), Sasaki (1992), and LaBrecque et al. (1996). Early adaptations of the technique to the field of geophysics were by Pelton et al., (1978), Dines and Lytle (1981), Tripp et al. (1984), Wexler et al., (1985). Adaptations for medical diagnostics can be found in Isaacson (1986), Barber and Seager (1987), and Yorkey et al., (1987).

LaBrecque et al. (1999) describe a three-dimensional inversion algorithm which calculates electrical resistivity; this algorithm is used for the work described herein. A two dimensional algorithm is also used in this work, as described in Ramirez et al. (1996).

Here we only summarize the general structure of the algorithms used for this work. First, a numerical model of the subsurface electrical resistivity is assumed, and the voltage field is calculated. These calculated voltages are compared to those measured; they will be different because the computer model of the subsurface is only an initial guess. The model is then changed in such a way as to make the voltages calculated for the new model closer to those measured. The algorithm continues making changes to the numerical model, improving agreement between calculated and measured voltages. This iterative process is 
continued until the agreement is within some specified value that is related to the accuracy of the measured values.

\section{Site Description}

The field experiments were performed under a $15.2 \mathrm{~m}$ diameter steel tank mockup located at the Hanford Reservation (200 East Area). Figure 1 shows the tank's location and the electrode layout at the leak detection experiment site. This empty steel tank contained several built-in spill points. Sixteen boreholes with eight electrodes in each surrounded the tank. The electrodes were located in $10.7 \mathrm{~m}$ deep boreholes starting at the ground surface and spaced every $1.5 \dot{2} \mathrm{~m}$. The diametrical distance between boreholes was $20.3 \mathrm{~m}$.

This report describes the results obtained during a brine release experiment conducted during July and August, 2001. Sodium thiosulfate solution was released several times at the center of the tank. ERT was used to monitor the first release and two of the last three releases.

\section{Experimental Approach}

ERT data surveys were collected before, during and after a brine release in each of the 16 electrode arrays. The data were used in three different ways:

1- Develop a fast and simple 'yes/no' indication of a leak. This approach can be performed in the field immediately after the data is collected, and the results are available in seconds. Each transfer resistance measurement is multiplied by an appropriate geometrical factor to generate an apparent resistivity and the geometric mean of these values for a given data set represent a single value, $\mathrm{R}_{-}$, that is representative of the electrical bulk or average resistivity beneath the tank. As conductive fluid accumulates beneath the tank, reducing the bulk resistivity, $\mathrm{R}$ is a single number representing subtank conditions that can be used as a simple metric of the presence or absence of a leak. It would be used only by comparing 
conditions during sluicing to conditions before sluicing (baseline) when the tank was presumed not to be leaking. This means that any leak present at the time of the baseline would not be detectable but leakage subsequent to the baseline would be detectable. This method would yield no information about the location or movement of a plume but will reliably identify the presence of a leak.

2- To get a high resolution image of plumes formed by leakage and use this image to estimate leakage volume and monitor plume migration: All measured values of transfer resistances (1620 in all) are used to reconstruct a three-dimensional tomographic image of the soil's electrical resistivity. This approach allows us to delineate the changes in resistivity created by the salt-water release. The tomograph anomalies will reveal the presence or absence of a leak as well as indicate the position and size of the plume. We realize that this approach requires considerable additional infrastructure around a tank. This approach offers the most information: leak detection by the presence of a statistically significant conductive anomaly, leak location by the position of the plume, approximate leaked volume from the size of the anomaly, and information about the speed and direction of the plume movement, and the flowpath(s) that it follows.

3- Develop low resolution 2D images of a plume using steel case boreholes (i.e., dry wells): All of the electrodes in each vertical array are connected together at the surface to form an electrical short circuit. As a result, each vertical array behaves electrically like a steel-cased well in a tank farm. With this methodology, a series of dry wells could be used to produce a low resolution, two-dimensional tomographic image of subtank electrical resistivity. Such an image could be used to detect the presence or absence of a leak and provide only a rough estimate of the plume size and horizontal position. This approach would require little or no additional infrastructure for tank monitoring. 
For cases 2 and 3 above we calculate the changes in the soil's electrical resistivity by comparing two data sets: 1) one for the case where a plume caused by a tank release is present, and 2) a corresponding data set for the case where there is no plume. This comparison was accomplished by subtracting, pixel by pixel, images of a baseline and some later condition.

Results and Discussion

Leak Detection

Electrical resistivity methods may be used in several ways to detect tank leaks. In this section, we will discuss three methods that we have tried during this study. The first is a very simple, non-imaging method to produce a leak alarm using the raw ERT data. The second is a method using only dry wells located near the tank to detect the presence of and produce a low-resolution image of a plume forming under the tank. The third method is 3 dimensional reconstruction of data from the ERT arrays to produce high resolution images of plume formation and migration. At the end of this section we will discuss the issues of detecting a new leak after other leaks have occurred.

\section{A Very Simple Leak Alarm-- Geometric Mean Apparent Resistivity}

External tank leak detection methods rely on changes in the soil under the tank caused by the release of tank fluids. These fluids are very conductive and small quantities will change the electrical properties of the soil in measurable ways. However, it is not necessary to reconstruct an image of the plume to detect its presence. Each measurement of resistivity under the tank contains a portion of the total information and it is possible to calculate a weighted average of these data to obtain a single number (apparent resistivity) representing the bulk conductivity under the tank at any single time. To do. 
this, we weight each resistance measurement by a geometrical factor, transforming it into the resistivity that would be necessary to produce the measurement if the soil were entirely uniform. This weighting factor is only a function of the geometrical arrangement of the electrodes. It is found by solving the forward electrostatic problem, for a homogeneously resistive half space.

$$
\rho=G R_{t}
$$

Here $\rho$ is the resistivity, $R_{t}$ is the measured transfer resistance and $G$ is the geometrical or weighting factor (see Keller and Frischknecht, 1966, or Hearst et al., 2000). It can be shown that:

$$
G=2 \pi\left(\frac{1}{C_{1} P_{1}}-\frac{1}{C_{1} P_{2}}-\frac{1}{C_{2} P_{1}}+\frac{1}{C_{2} P_{2}}\right)
$$

where $\mathrm{C}_{1} \mathrm{P}_{1}$ is the distance between the positive current pole and the positive potential pole, $C_{1} P_{2}$ is the distance between the positive current pole and the negative potential pole, $\mathrm{C}_{2} \mathrm{P}_{1}$ is the distance between the negative current pole and the positive potential pole, and $\mathrm{C}_{2} \mathrm{P}_{2}$ is the distance between the negative current pole and the negative potential pole.

Using these equations, we calculate the geometric mean of these normalized data. As the soil becomes more conductive this number will decrease in value.

Figure 2 shows the geometric mean apparent resistivities during the first and last release. The values show a decrease from August $8^{\text {th }}$ (baseline, before the first release) to August $11^{\text {th }}$ (in the morning, near the end of the first release). We interpret this steady decrease as evidence for a developing plume of salt water beneath the tank. 
We did not acquire data between August $12^{\text {th }}$ and $18^{\text {th }}$. For the last release, between August $19^{\text {th }}$ and $23^{\text {rd }}$, the data show a similar behavior as before. Here again we interpret this data as evidence for additional salt-water release. In this sequence, however, the last point implies an increase in bulk electrical resistivity under the tank at the end of the release. The cause for this increase is unknown although we speculate that part of the plume may be moving so that our assumption of uniform resistivity produces inconsistent conditions for the last two points.

This simple analysis yields no quantitative information about plume volume or location. On the other hand, it is simple and quick--a mean can be calculated within moments of data collection. This approach might be useful for signaling the need for more extensive leak detection such as ERT imaging using either the dry wells or using ERT electrode arrays.

Approximate Plume Images Using Dry Wells

Using dry wells as electrodes, it is possible to reconstruct approximate 2 dimensional images under a tank and use these to detect the presence of a leak. To demonstrate how this is done, we used the ERT electrode arrays with all eight electrodes in each array connected together (forming an electrical short circuit) to make 16 long electrodes. The electrical equivalent of this arrangement is shown in Figure 3. Connecting all electrodes together in an array formed an electrical approximation to a continuous steel pipe or dry well. Although this approximation might seem crude, it is actually quite good-an array with point electrodes separated by 8 feet but connected together, and a continuous steel pipe, will look very similar at a distance of 15 or 20 feet. This configuration is entirely adequate to demonstrate the point that dry wells can be used for crude imaging. 
Figure 4 shows the results for the release conducted between $0747 \mathrm{hrs}$ on August $20^{\text {th }}$ and $0742 \mathrm{hrs}$ on the $21^{\text {st }}$. These difference images, relative to the baseline on the $19^{\text {th }}$, constitute maps of the 3D volume under the tank projected unto a horizontal 2D plane. Only this two dimensional reconstruction is meaningful because the electrodes are 35 feet long.

There is a clear progression of conductivity changes with time during the experiment. The first difference image is for a no-change condition and it is therefore blank because the data were taken about $8 \mathrm{a} . \mathrm{m}$. on the $20^{\text {th }}$, before the release started at noon. Then at $1233 \mathrm{hrs}$, just after the release started, there is a weak anomaly extending from the release point at the center toward the Northeast. That anomaly becomes stronger by $1320 \mathrm{hrs}$. By 1422 hrs, the anomaly all but disappears, implying that the water was shut off for a short time and the plume drained out of the image volume. Since such fast drainage is unlikely, even with no inflow, we don't have a good explanation why the plume anomaly weakened at $1422 \mathrm{hrs}$. A similar effect is observed at $1621 \mathrm{hrs}$ on that day. Notice that the strongest anomaly is at $1658 \mathrm{hrs}$ on the $20^{\text {th }}$. The next morning the anomaly was much weaker, implying a lower flow rate during the night of the $20^{\text {th }}$.

A possible explanation for the occasional disappearance of the anomaly is that the signal measured by the long electrodes is weak. In the appendix, we show the results of numerical modeling for the long electrodes case. The modeling shows that when long electrodes are used most of the current flows through the tank shell and only a small fraction flows through the soil. This means that there relatively little sensitivity to the soil properties. The diminished sensitivity may be a reason why the image anomalies in Figure 4 behave in the manner shown.

The same analysis that we have described above for the case of August $19^{\text {th }}$ baseline was repeated using an August $10^{\text {th }}$ (at $1036 \mathrm{hrs}$ ) baseline. This data was taken during, not 
before, the initial release but it is the first usable data acquired during the experiment (earlier data, including the intended baseline, was taken with a saturated current monitor amplifier, and thus is untrustworthy). Although the baseline on August $10^{\text {th }}$ is not ideal, it was taken approximately 24 hours after the release started and therefore can be used to show changes after the first day of the release.

Figure $4 \mathrm{a}$ shows the entire sequence of long electrode ERT using the August $10^{\text {th }}$ baseline. Resistivity changes from the first release are first detected by the data taken early on August 11. It appears that the plume is forming near the center of the tank. By August $20^{\text {th }}$ at $1230 \mathrm{hrs}$, a little over one day into the second release, the plume is in the same place but now presents a much stronger conductivity contrast. Subsequent images show a persistent anomaly from the plume but with some variations in strength and size from the combined effects of added brine and drainage.

The same analysis shown in Figure 4a was repeated using data from only 8 of the long electrodes; these results are shown in Figure 4b. The full data set was decimated to include every other electrode in the array to simulate the case for long electrode ERT from only 8 dry wells. We note here that this decimated data set contains only 20 linearly independent measurements, $25 \%$ of data for the previous case, which severely limits its ability to constrain the solution. We should, therefore, expect to see results of reduced contrast, sensitivity and resolution. Recognizing this limitation, we see that the results are consistent with those of Figure $4 \mathrm{a}$. Now the plume from the first release is not detected. With this reduced sensitivity, the plume first appears on August $20^{\text {th }}$ (note that no measurements were made between $8 / 11$ and $8 / 19 / 01$ because the site was being used by other investigators), more diffuse but still offset from the tank center. Subsequent images show a persistent anomaly but most detail of variations in strength, size, and location are lost. 
High Resolution Images of Plumes-Using ERT Electrode Arrays

\section{Differences in resistivity relative to baseline surveys:}

We now shift our attention to the resistivity changes mapped using the point electrode arrays. For these images, 120 electrodes located in 16 boreholes were used to survey the subsurface. We consider these to be the best results of all the approaches discussed so far in terms of accuracy, sensitivity, and resolution.

We will first discuss the changes caused by the first release as well as the first three combined (shown in Figure 5) and then discuss the changes caused by fourth and fifth releases (Figure 6). The images in Figure 5 show the changes relative to a reference image collected on $8 / 8 / 01$, just prior to the start of the first release. The size of the image block shown is $20.3 \mathrm{~m}$ wide by $20.3 \mathrm{~m}$ deep and $10.7 \mathrm{~m}$ tall. The red dots on top of the block indicate the location of the electrode arrays used. The results are shown in the form of $\log 10$ resistivity ratios (i.e., $\log _{10}\left(\frac{\rho_{s, a}}{\rho_{s, b}}\right)$ ) where $\rho_{s, a}$ is the resistivity after the release started and $\rho_{s, b}$ is the resistivity of the baseline. The top 2 rows of images display the same results displayed using different transparency levels. The white bar across the color bar indicates the range of values that are rendered transparent. Note that when the change relative to the baseline is 0 ; the ratio is 1.0 and the $\log 10$ of the ratio is 0 . Decreases in resistivity (expected to be associated with the plume) are indicated by ratios below 1.0 $(\log 10$ of the ratio below 0.0$)$. The bottom row of images in the figure shows a vertical slice below the release point (marked by vertical arrow pointed downward).

The first four columns of images in Figure 5 show the changes observed by the first release which ended sometime after the $8 / 11 / 01$ data was collected. The fifth column (dated $8 / 19 / 01$ ) shows the cumulative changes caused by the first three releases. The 
figure suggests that a plume, represented by resistivity decreases, develops as the volume of released fluid increases. The plume migration grows primarily downward and to the Northeast. Approximately 8 hours after the start of the first release (afternoon of 8/9/01), clear indications of a plume can be observed on the second row of images. At the time of writing, the total volume released to this point is unknown, but it is expected to be of the order of a several hundred gallons. These results illustrate the ability of the ERT method to detect released volumes within this range. Also, the results suggest that the images may be useful in determining the approximate location of the hole in the tank, speed, flow direction and volume of the plume, and identify the soil regions that are being contaminated.

Now we consider the changes caused by the last two releases; these changes are shown in Figure 6 . The baseline tomograph used to calculate the change is for $8 / 20 / 01$, collected before the fourth release started. The fourth release occurred between noon on 8/20/01 and 11:37 AM on 8/21/01; approximately 360 gallons were released. The first two columns in Figure 6 show the resistivity changes caused by this release. The first column shows changes where most of the 360 gallons have been released because the data was collected around $9 \mathrm{AM}$ on the $21^{\text {st }}$. The images indicate that, by the end of the release, a plume is forming below and to the NE of the release point. This result confirms our earlier claim (Ramirez et al., 1996): that plumes of the order of a few hundred gallons are detectable with this approach.

The next release started on 8/21/01 at around 2:40 PM and lasted until noon on 8/23/01. The images on the third and fourth columns show the cumulative effects of the 8/20-21/01 and $8 / 21-23 / 01$ (the $4^{\text {th }}$ and $5^{\text {th }}$ ) releases. The finger continues to grow towards the NE. When compared to the plume created by the first release (Figure 5), these images seem to suggest that the plume is moving sideways more (to the NE) and less downward. 
The same analysis that is shown in Figure 5 was repeated using data from only 4 point electrode arrays. The full data set was decimated to include every fourth of the 16 electrode arrays to simulate the case for 3D ERT from only 4 arrays. Just as for the decimation of the long electrode data discussed above, decimation of the point electrode data leaves us with about $25 \%$ of the original data, thereby decreasing the information that constrains the parameters in a $3 \mathrm{D}$ inversion. As a result we should expect results of reduced sensitivity, contrast and resolution.

Figure $5 \mathrm{~b}$ shows the results of this analysis. The images in Fig. $5 \mathrm{~b}$ have a "blocky" look to them because we chose to use larger parameter blocks in order to reduce the number of unknowns in the inversion problem. The first row of images in Fig. $5 \mathrm{~b}$ is shown using the same color scale and transparency as the images in the second row of Figure 5. It is clear that we see changes earlier (lower released volume) in Figure 5 than in Figure 6. This means that using a larger number of arrays increases the sensitivity to the plume. For the 8/20/01 results, the volume observed in Figure 5 is smaller than in Fig. $5 b$ because the larger number of arrays allow better resolution of the image.

The images show similar trends to those observed for the 16 array images in Figure 5. Both image sets show anomalies that increase in volume as the volume of released brine kept increasing. Both also show significant changes located directly below the release point. From these comparisons we conclude that it is possible to produce useful images of the plume using only four vertical electrode arrays. However, fewer arrays produce fewer data with which to constrain the inversion and decreased sensitivity and resolution.

The discussion so far has centered on resistivity differences relative to a baseline tomograph. We now explore the question of whether it is possible to map pre--existing plumes without the benefit of baseline surveys. Figure 7 shows the absolute values of resistivity measured during the course of the releases. The figure at the top shows the 
resistivity values corresponding to $8 / 8 / 01$ before all the releases. The bottom row of images show the resistivity measured as more solution is released. Note the region of high conductivity (low resistivity) corresponding to the tank metal. Below the tank's bottom one can clearly see regions of low resistivity that emanate from the tank. These regions are approximately vertical and become less resistive with time. We believe that these results raise the possibility that pre-existing plumes under tanks may be detectable without the need of baseline data. This capability may make possible the detection of pre-existing plumes under the tanks at Hanford.

\section{Detection Limits and False Alarms}

Establishing the limits of any leak detection system is very important because of the consequences of a detection error. A false negative result would mean a lack of sensitivity in the method, so that a significant leak might be present but not detected. For this case, it is important to determine the minimum leak volume that can be reliably detected in the presence of all its associated errors and uncertainties. A false positive result would mean that the method is detecting leaks that are not real (giving false alarms) because it is sensitive to conditions not related to a leak and there is no way to differentiate between them and a leak.

Our interpretation approach assumes that all detected changes in soil resistivity are due to a tank leak or to data error. False alarms as well as tomograph sensitivity can be addressed by performing an analysis of the effects of measurement error on the images. Error analysis will indicate a threshold (in terms of released volume) above which the results are reliable. We define the minimum detection volume as this threshold.

Tank managers may also choose to add a "factor of safety" to this threshold. If the goal is to minimize disruption to a sluicing operation and only act when large leaks are likely to 
be present, one may chose to define an alarm threshold that is several times larger than this sensitivity threshold. This means that a leakage prediction would be issued only after the analysis showed changes equal to the alarm threshold. Setting the alarm threshold at a given number may be based on the detection limits of the method and the operational goals of the tank managers. We mention this arbitrary criterion here to demonstrate how the analysis might be done to set an alarm threshold that might be useful for actual tank operations.

For the geometric mean analysis, we determine the sensitivity threshold and the alarm threshold by generating the mean using only the normal data and then again using only reciprocal data for a given time. The difference between these two means is considered the sensitivity threshold. If the geometric mean at two different times differs by more than this amount, we conclude that a statistically significant change in subtank soil resistivity has occurred and we interpret that as a developing leak for the time interval. This is our sensitivity threshold. Analysis of the data displayed in Figure 2 yields sensitivity threshold of $+-0.2 \mathrm{ohm} \mathrm{m}$, as indicated by the scatter of the points around the diagonal line shown. Points that plot along the diagonal line indicate a perfect match between the normal and reciprocal. The distance between any point and the diagonal (along a line perpendicular to the diagonal) indicates the degree of mismatch between the results.

Of special interest to tank operations is the false alarm rate of a leak detection method. To determine the false alarm rate, we would compare our alarm rate to the history of water injected (or not injected) during the test. At the time of writing, we do not have injection rates for this test so cannot determine a false alarm rate at this time.

The geometric mean data satisfy not only the sensitivity threshold test but also satisfy our ad hoc alarm threshold test. The very first mean value at $580.8 \mathrm{ohm} \mathrm{m}$ which represents a baseline and the second mean value at $572.4 \mathrm{ohm} \mathrm{m}$ are different by more 
than 3 times $0.2 \mathrm{ohm} \mathrm{m}$, implying that the difference is statistically significant for a leak alarm—not a false alarm.

We could produce a similar threshold analysis from an error analysis on the long electrode reconstructions (see Figure 4). Now, however, the analysis requires a quantitative comparison of reconstructed images instead of two numbers. This work is in progress but we have not been able to complete the comparison for this preliminary report.

However, a qualitative comparison will demonstrate the principles involved and probably leads to the same conclusion. Figure 8 shows the same sequence of long electrode data as shown in Figure 4 except that the top row uses only the normal data and the bottom row uses only reciprocal data. For each time given, there are noticeable differences between the two reconstructions. However, comparing Figures 4 and 8 it is also clear that the anomalies detected during the leak are clearly larger in magnitude than the differences seen in the threshold analysis. We therefore conclude that the anomalies in Figure 4 are above the threshold limit and thus statistically significant. These anomalies would then be considered as reliable indicators of leakage.

Now we turn our attention to sensitivity limits for the 3D ERT analysis. As discussed previously, our strategy in determining the trustworthiness of the detected electrical resistivity changes is based on the concept of reciprocity. Each data set collected contained data that is fully reciprocal; i.e., for each measurement, its reciprocal measurement was collected. When one compares images calculated using reciprocal data sets, an estimate of how closely the data obeys Ohm's law is obtained. This approach also quantifies how measurement errors propagate through the data inversion process, and provides an estimate for the threshold of changes in the images that are likely to be reliable. 
Figure 9 shows the results of our reciprocal analysis for the 3D images. The figure quantitatively compares the resistivity in the "normal" tomograph (tomograph calculated using only the first measurement in a pair of reciprocal measurements) and in the "reciprocal" tomograph (tomograph calculated using the second measurement in a pair of reciprocal measurements where the transmitter and receiver dipoles have been switched). Specifically, the values plotted along the $X$ and $Y$ axes are of the form $\log _{10}\left(\frac{\rho_{s, a n}}{\rho_{s, b, n}}\right)$ and $\log _{10}\left(\frac{\rho_{s, a r}}{\rho_{s, b, r}}\right)$, where $\rho_{s, a, n}, \rho_{s, b, n}$ are the tomograph resistivities using the normal data, and $\rho_{s, a, r}, \rho_{s, b, r}$ are the tomograph resistivities based on the reciprocal data. All voxel values in the region between the boreholes are shown. A perfect match between these two tomographs would be indicated if all symbols plotted along the central dashed line shown. Values that plot away form this line indicate an imperfect match between voxel values and give a measure of the degree of the mismatch. The two lines on either side of the central dashed line indicate the range of values in which there is a mismatch. We will use this mismatch as an estimator of the reliability of the ERT results.

Figure 9 shows the results of this analysis for the changes early during the fourth release ( $\rho_{s, a}$ corresponds to the tomograph for $8 / 21 / 01$, and $\rho_{s, b}$ corresponds to the tomograph for $8 / 20 / 01$ ). This plot suggests that that the vast majority of voxel values agree within $10^{+/-0.2}$ (resistivity ratios between 0.63 and 1.58 ). We believe this is the sensitivity threshold for these images.

We will now use the results of this analysis to evaluate the ability to reliably detect the plumes. The approach we have followed is to render transparent any voxel values that fall within the range of values defined above. Referring to Figures 5 and 6, we can now justify the levels of transparencies chosen. The top row of images shows as transparent all ratio values greater than $10^{-0.2}$; this value is based on the $10^{+/-0.2}$ threshold determined from the 
fourth release tomographs- the sensitivity threshold. The second row of images in the figures shows as transparent all ratio values greater than $10^{-0.1}$-a level arbitrarily chosen at half the expected error.

During the first release (Figure 5), the top row of images shows that reliable anomalies are observed for images corresponding to 8/10/01 AM and later times. On the other hand, if we choose the second row of images (half the sensitivity threshold), all images (including the 8/9/01 PM image show changes that are considered reliable. Because the released volume is unknown we cannot determine the sensitivity threshold for the leak volume.

We can do a similar assessment for the images corresponding to the fourth and fifth releases (Figure 6). The image corresponding to 8/21/01 (around 9AM) represents the case where roughly 300 gallons had been released (this is a rough estimate since all we know at the time of writing is that 360 gallons were released between noon 8/20/01 and 11:30 AM, 8/21/01). All images in the top and middle rows of images in Figure 6 show credible changes. Therefore, the minimum detectable volume is about 300 gallons; it could be less than that because the estimate depends on how often the surveys were repeated.

In summary, an analysis of image reliability suggests a minimum detectable volume for 3D ERT of approximately 300 gallons (possibly less). When the minimum detectable volume has been released, a false negative interpretation becomes very unlikely. The reciprocity analysis described also minimizes the possibility of false-positive (false alarm) interpretations because it provides an estimate of reliability on the observed changes and minimizes the possibility that resistivity changes caused by measurement error are interpreted as leaks. 
Estimates of Release Volume and Flow Rate

Estimating the volume of the plume (i.e., the volume of soil invaded by the released solution) is relatively easy. One simply sums the volume of all voxels that exhibit a level of change that is determined to be credible. However, tank managers are not interested in the plume volume; they are very interested in knowing the released volume (i.e., the volume of liquid tank wastes that have leaked). Estimates of released volume require that we use the volume of the plume together with a petrophysical model to estimate released volume.

The petrophysical model we chose is widely accepted and is known as 'Archie's' equation (Hearst et al., 2000). This model relates the soil's resistivity $\left(\rho_{s}\right)$ to the soil's saturation $(S)$, porosity $(\phi)$, and pore fluid conductivity $\left(\rho_{w}\right)$ as follows:

$$
\frac{\rho_{s}}{\rho_{w} \phi^{-m}}=S^{-n}
$$

The exponents $\mathrm{m}$ and $\mathrm{n}$ are empirically derived constants. Given that we are primarily interested in changes and that porosity is unlikely to change, we can derive the following equation:

$$
\frac{S_{a}^{-n}}{S_{b}^{-n}}=\frac{\rho_{w, b}}{\rho_{w, a}} \frac{\rho_{s, a}}{\rho_{s, b}}
$$

The subscripts $\mathrm{b}$ and a indicate conditions before and after the soil's property change due to fluid invasion. Hearst et al. indicate that the exponent $\mathrm{n}$ is generally determined based on laboratory data and when such data is unavailable, an acceptable value is about $2.0 \mathrm{H} / \mathrm{-}$ 0.5 . Once the change in change in saturation is established, the change in pore water volume can be calculated as follows: 


$$
\Delta V_{w}=\left(\frac{S_{a}}{S_{b}}-1\right) S_{b} \phi V_{v}
$$

where $\Delta V_{w}$ is the change in the volume of water in each tomograph voxel and $V_{v}$ is the volume of the voxel. Then, we sum $\Delta V_{w}$ over all voxels that exhibit $\frac{\rho_{s, a}}{\rho_{s, b}}$ that have been determined to be credible. In most cases, good estimates of $S_{b}$ and $\phi$ can be obtained from geophysical well logs (neutron) and /or laboratory measurements made on core.

Equation 2 says that in order to calculate $\frac{S_{a}}{S_{b}}$ (change in saturation), we need to know $\frac{\rho_{w, b}}{\rho_{w, a}}$ (the change in pore water conductivity) and the changes in soil resistivity $\left(\frac{\rho_{s, a}}{\rho_{s, b}}\right)$. This implies that from one known value $\left(\frac{\rho_{s, a}}{\rho_{s, b}}\right)$, we need to estimate two unknown values. Clearly, this calculation cannot be performed unless one assumes the value for $\frac{\rho_{w, b}}{\rho_{w, a}}$.

We will use equations 2 and 3 to estimate $\Delta V_{w}$. An estimate of $\frac{\rho_{w, b}}{\rho_{w, a}}$ will be obtained for one release where the volume released was known; this estimate will be the average change in pore water conductivity over the whole tomograph volume. We will assume that for the other releases where an unknown volume of solution was used, the same value of $\frac{\rho_{w, b}}{\rho_{w, a}}$ applies. For the release that started on $8 / 20 / 01$ and ended on $8 / 21 / 01$, a total of about 360 gallons were released. 
When the following assumptions are made:

\begin{tabular}{|l|r|}
\hline Porosity, $\phi$ & 0.25 \\
\hline "before" water resistivity, $\rho_{w, b}$ & 30 ohm-m \\
\hline "after" water resistivity, $\rho_{w, a}$ & 21 ohm-m \\
\hline Exponent, n . & 2 \\
\hline initial saturation, $S_{b}$ & 0.25 \\
\hline
\end{tabular}

the estimated volume released is 290 gallons. This estimate is in reasonable agreement with the true volume. We will assume the same values apply to other releases.

We will next provide volume estimates for two "blind releases" were volume released is unknown at the time of writing. For the release that started on $8 / 09 / 01$, the estimated released volume on 8/11/01 at around 9:00 AM is 1260 gallons. For the release that started during the afternoon of $8 / 21 / 01$, the estimated released volume on $8 / 23 / 01$ at around 9:00 AM is 1550 gallons.

We consider the above estimates as coarse approximations due to the large number of assumptions that are required and due to distortions to the plume size caused by the inverse solution.

The ERT methods discussed here are not directly capable of estimating the leak flow rate. Neither Archie's equation (equation 2) nor any other petrophysical model that we are aware of indicates that soil resistivity is a direct function of flow rate. Indirectly, it is possible to get a qualitative flow rate estimate by looking at the increases in released fluid 
volume (as determined the analysis above) as function of time. From this simple approach we estimate an average flow rate of $50.4 \mathrm{gal} /$ hour for the $1^{\text {st }}$ release (average flow rate between $8 / 9 / 01$ and $8 / 11 / 01$ in the morning) and 46.3 gal/hour for the $5^{\text {th }}$ release (average flow rate between the afternoon of $8 / 21 / 01$ and morning of $8 / 23 /$ ).

\section{Conclusions and Recommendations:}

We have demonstrated that electrical resistance measurements can be used in three quite different ways to detect changes in electrical conductivity under the test tank. Without knowing details of the released volumes, the results support the conclusion that the conductivity changes we detect arise from released fluids and from this we infer that these methods are good candidates for leak detection at single shell tanks. We have also shown how statistical limits can be set on sensitivity (minimum detectable volume) and how these limits can be used to evaluate the possibility of false positives and false negatives. In addition, ERT images have been used to estimate total released volume and flow rates for two "blind tests". The results presented here indicate that ERT provides useful information about tank leaks.

These results point to one possible operational strategy for ERT use in tank farm operations: the geometric mean of the apparent resistivity can be measured quickly and often (using either the dry wells or point electrode arrays installed for ERT) as a 'quick look', non-imaging capability. When this analysis suggests that observed changes are above the sensitivity threshold, more detailed electrical data could be taken, and this additional data could be used for imaging. From dry wells, one could obtain low-resolution 2D images that may be useful to yield the leak location. From ERT arrays, one could get higher resolution 3D images that may be useful for leak location and plume size (which could be used to estimate leak volume). 
We have shown that ERT can be used in two ways. The first approach involves the use of dry well casings as long electrodes. We have shown results using 8 and 16 long electrodes. Both show reliable evidence of the brine releases, but the 16 electrode results offer substantially higher sensitivity and resolution. It may be possible to perform similar surveys with as few as 6 dry wells; however, this scenario is likely to be quite challenging and needs to be properly investigated before it is selected.

The second approach involves the use of vertical electrode arrays around a tank. These arrays could be deployed using CPT or standard drilling technology. We have evaluated the case where 4 and 16 electrode arrays are used. Both of these provide much better resolution than dry well survey scenarios. The results based on data from 4 arrays yield useful plume images. Comparisons with the 16 array images indicate that the 4 array images offer substantially less resolution and sensitivity. We believe that better sensitivity and resolution can be achieved when the 4 electrode arrays cover a substantially longer vertical distance than the $10.7 \mathrm{~m}$ length of the existing arrays at the site. This allows the use of a higher number of electrodes, and the encirclement of the target region with electrodes thereby increasing the information available about the plume.

Recent work we have done on a different but related project has lead us to believe that it may be possible to detect leaks using ERT from measurements taken entirely outside of a tank farm. This method would have reduced sensitivity and resolution compared to the 3D ERT in this report, but it would require no additional infrastructure inside the tank farm fence-line Figure 10 shows the ERT image of a tank sitting on the surface, leaking jet fuel (kerosene). The data were collected on electrodes arranged around the periphery of the tank in such a manner that currents were made to flow under the tank. An electrically similar strategy would be to use electrodes arranged around the periphery of a tank farm (outside the fence) so that current is made to flow under the buried tanks. We believe that 
this method, or simple variations, could be used to detect large (thousand gallons) tank leaks. In addition, such a leak detection system could be used to monitor long term the changes in soil properties under of a tank farm.

\section{Points pertaining to possible FY2002 work:}

We have been requested to address the following points.

1) Reasons why the method should (or should not) be further investigated.

We believe that the ERT method is ideally suited to detect leaks under tanks and that it should be investigated further for the following reasons.

The method can be adapted to use existing infrastructure (dry wells) thereby reducing deployment costs.

ERT is a mature technology that has been demonstrated in a variety of geologic environments (including the Hanford site) and for a variety of applications. The capability to detect leaks under tanks at Hanford has been demonstrated in 3 separate trials at the Hanford site (Ramirez et al., 1996; Narbutovskih et al., 1996; Ramirez and Daily: this report). The method can detect leaks of the order of several hundred gallons of brine.

Under routine operating conditions, one person can operate the system. Once the system is permanently connected to electrodes within the farm, the operator remains outside the tank farm fence. The ERT data collection process does not require the movement of sensors or probes and so can easily be automated, thereby reducing the need for field personnel.

\section{2) Next steps in deployment.}

The performance envelope of the technology with respect to false-positive and false negative detection needs to be investigated. 
We need to fully investigate the technique's performance under "low data" conditions. These conditions are expected when few electrode arrays $(<=6)$ are available or when few dry well casings are available. In these situations, relatively little linearly independent data can be collected, thereby reducing the technique's robustness, sensitivity and resolution. The effects of "low data" need to be evaluated using numerical models as wells as field trials.

The technology can be evolved to allow full autonomous/remote operation where the data collection system can be operated without the need for on-site personnel. The system requirements and preliminary costs for such a system need to be developed.

We believe the ERT method can be adapted to detect large leaks (1000+ gallons) using electrodes located outside the fence of tank farm. In this scenario, the cost of deploying borehole electrode arrays should be substantially lower. This scenario needs to be properly evaluated using numerical simulations, physical models and field trials.

3) Estimated costs of further studies relating to deployment.

We estimate these costs to be approximately $\$ 350,000$ over the next calendar year. The work scope includes activities described in "Next steps in deployment' as well as in participation in field trials planned for FY02. We assume that the field trails will require monitoring over a 5-7 month period at a simulated leaking tank.

As per B. Barnett email request (1/16/02) for estimated costs of deployment in a tank farm, we have assumed that a test lasting 20 days will be conducted. There will be 4 vertical electrode arrays available around the tank that will be provided and installed by PNNL. We have assumed that this test will be concurrent with other tests at the Mock Tank site. LLNL will provide the 
measurement electronics and personnel for data acquisition, data processing and analysis, and reporting. The estimate for this work is an additional $\$ 70,000.00$.

4) Estimated (order of magnitude) cost of a permanent operating system.

We estimate the cost of a permanent data acquisition system to range between $\$ 50000$ and $\$ 150000$. The costs of deploying electrodes (if any), the costs of the wiring between the electrodes and data acquisition system, and the costs of data processing hardware and software are not included in this estimate.

5) Anticipated problems with deployment in culturally "noisy" areas such as a tank farm.

One issue that needs to be investigated is the interaction between the cathodic protection system used to mitigate tank corrosion and ERT data acquisition. Cathodic protection generates a DC field that may influence the validity of the measurements. Most state of the art data acquisition systems have the capability of correcting for DC signals of a few volts. If the DC field generated by cathodic protection exceeds the measurement system limit, this issue will have to be addressed.

Another possible problem may be the presence of water leaks unrelated to a tank. Normal operations may inadvertently release water into the subsurface that may create electrical resistivity changes similar to released tank waste. Subsurface water mains in the area may release large amounts of water that may create similar changes.

6) Requirements for development of a remotely activated detection system, so as to minimize on site personnel.

We believe that a typical ERT system will minimize on site personnel because the system will be located and operated from outside a tank farm. Wires will connect the electrodes within the farm to the measurement system outside. 
For tank remediation monitoring, a single ERT operator can easily perform surveys with the all needed equipment located in an equipment trailer or office located outside the farm's perimeter. This means that current ERT systems already achieve the goal of minimal on-site personnel.

A remotely activated system makes sense to be considered for the case of long term monitoring of a tank farm. In this case, the soil under the tanks would be monitored for unexpected changes for periods of many of years. A remotely activated system would eliminate the need for onsite visits to perform surveys thereby reducing personnel costs.

We believe that it is technically and economically feasible to develop an autonomous ERT system that would monitor electrical properties around an active $\operatorname{tank}(\mathrm{s})$. While the development of this field-monitoring capability is new, it constitutes an extension of already-proven technology, and has a high expectation for success. This method could also be used with either vertical electrode arrays or long electrodes (casings) that may already be present or those that may be added around a $\operatorname{tank}(\mathrm{s})$. Data interpretation is accomplished using existing computer codes that treat the fully $3 \mathrm{D}$ case (the codes have been tested for over 5 years under a variety of conditions). The products will be time dependent maps of the changes in formation resistivity caused by tank waste released. The relatively inexpensive data acquisition system (permanently installed in the field) can be designed to operate autonomously. When information is desired, the operator can call the system up, initiating an acquisition sequence. The system will acquire data in an unattended mode, store and transmit the data stream and shut itself down. Alternatively, the system can be programmed to obtain data periodically on its own. 


\section{References}

Daily, W. and E. Owen, 1991, Cross-borehole resistivity tomography, Geophysics, 56, 1228-1235.

Dines, K. A. and R. J. Lytle, 1981, Analysis of electrical conductivity imaging, Geophysics, 46, 1025-1036.

Hearst, J., P. H. Nelson, and F. L. Paillet, 2000, Well Logging for Physical Properties, Second Edition, John Wiley \& Sons, Chicester, England

LaBrecque, D., Morelli, G., Daily, W., Ramirez, A., and P. Lundegard, 1999, Occam's Inversion of 3D Electrical Resistivity Tomography", in Three Dimensional Electromagnetics, eds. M. Oristaglio, and B. Spies, Soc. Expl. Geophys.

Narbutovskih, S., D. Iwatate, M Sweeney, A. Ramirez, W. Daily, R. Morey, L. Christensen, 1996, Feasibility of CPT deployed Vertical Electrode Array in Single Shell Tank Farms, Westinghouse Hanford Co., WHC-SD-EN-TA-004, Rev. 0, Richland, WA.

Oldenburg, D. W. and Y. Li, 1994, Inversion of induced polarization data, Geophysics, 59 , 1327-1341.

Pelton, W. H., L. Rijo and C. M. Swift, Jr., 1978, Inversion of two-dimensional resistivity and induced-polarization data, Geophysics, 43, no. 4, 788-803, June.

Ramirez, A., W. Daily, A. Binley and D. LaBrecque, 1999, Electrical impedance tomography of known targets, J. Env. Eng. Geoph., 4, 11-26.

Ramirez, A., W. Daily, A. Binley, D. LaBrecque and D. Roelant, Detection of Leaks in Underground Storage Tanks Using Electrical Resistance Methods, (UCRL-JC-122180, October, 1995), J. Engineering and Environmental Geophysics, 1, 189-203, 1996.

Ramirez, A., W. Daily, A. Binley, D. LaBrecque and D. Roelant, Detection of Leaks in Underground Storage Tanks Using Electrical Resistance Methods, (UCRL-JC-122180, October, 1995), J. Engineering and Environmental Geophysics, 1, 189-203, 1996.

Sasaki, Y., 1992, Resolution of resistivity tomography inferred from numerical simulation, Geophysical Prospecting, 40, 453-463.

Tripp, A. C., G. W. Hohmann and C. M. Swift, 1984, Two dimensional resistivity inversion, Geophysics, 49, 1708-1717.

Weller, A., M. Seichter, and A. Kampke, 1996, Induced polarization modelling using complex electrical conductivities, Geophysical Journal International, 127, 387-398. 
Wexler, A., B. Fry and M. R. Neuman, 1985, Impedance-computed tomography algorithm and system, Applied Optics, 24, no. 23, 3985-3992, December.

Yorkey, T. J., J. G. Webster and W. J. Tompkins, 1987, Comparing reconstruction algorithms for electrical impedance tomography, IEEE Trans Biomedical Engineering, $B M E-34$, no. $11,843-852$, November.

Yuval, and D. W. Oldenberg, 1997, Computation of Cole-Cole parameters using IP data, Geophysics, 62, no. 2, 436-448.

\footnotetext{
Appendix A

Estimates of changes in soil resistivity caused by plume infiltration

Infiltration of the sodium thio-sulfate solution caused increases in pore fluid salinity and increases in saturation. We have used Archie's (Hearst, et al., 2000) equation to estimate soil resistivity as a function of saturation and the pore fluid's resistivity. The results of this simple model are shown in Figure A.1. We calibrated the model to produce a bulk resistivity of $1000 \mathrm{ohm}-\mathrm{m}$ based on the resistivity logs measured by Applied Research Assoc. prior to the start of the FY 00 work at the Sisson and Lu site. The model assumed that the ambient properties were as follows: saturation was 0.4 , porosity was 0.3 and the resistivity of the ambient pore fluid was $30 \mathrm{ohm}-\mathrm{m}$ (a factor of 2.5 smaller than river water). Measurements of the resistivities for the various fluids considered are shown in Figure A.1.
}

The curves in Figure A.1 help illustrate that the primary mechanism affecting the measured changes in resistivity is the change in fluid salinity created by the highly conducting, sodium thio-sulfate brine. If we assume that the brine causes the fluid conductivity to change from $30 \mathrm{ohm}-\mathrm{m}$ to $0.1 \mathrm{ohm}-\mathrm{m}$ and there is 0.0 saturation change, the bulk resistivity changes a factor of 100 . Conversely, if the salinity remains fixed while the saturation changes from 0.4 to 1.0 , the bulk resistivity changes a factor of about 5 . This suggests that, for the case of sodium thio-sulfate infiltration, the tomographs of 
resistivity change are 20 times more sensitive to salinity changes than to saturation changes.

\section{Appendix B}

\section{Numerical modeling of current density - indicator of sensitivity}

It is important to understand how the sensitivity of the measurements varies within the region of interest to properly interpret images of electrical resistivity under a steel tank. The steel shell of the tank has electrical properties that are vastly different than those of the surrounding soil. These differences have a large effect on measurement sensitivity to changes occurring in the soil beneath the tank. We have performed numerical simulations to provide a qualitative understanding of measurement sensitivity to regions below the tank. We have used current density as an indicator of measurement sensitivity. Simply stated, the electrical measurements are most sensitive to regions in which current preferentially flows, i.e., regions of high current density.

Figure B.1 shows the results of the modeling. The drawings on the left column of the figure indicate the various electrode configurations considered. The modeling assumes that each electrode is injecting one ampere of current. Note that cases with and without the tanks are included (middle and rightmost columns of images). The top row of images in the figure shows the current density when two steel cased wells are used as long electrodes. The highest current densities occur along the steel shell and in the near vicinity of the steel casings. Relatively high current densities are also observed along the soil next to the tank's perimeter. The region of lowest current density occurs directly below the tank's center.

These results suggest that measurements made with long electrodes have the lowest sensitivity in the soil just below the center of the tank. The release point for the field 
experiment was located near the center of the tank. This means that the long electrode measurements had the least amount of sensitivity to the soil region invaded by the plume. This helps explain the relatively small changes measured with the long electrodes. Substantially higher sensitivity is expected for leaks that develop along the tank $\mathrm{s}$ perimeter.

The second and third rows of images depict the current densities for short electrodes located close to and away from the tank. These images also suggest that a most of the current is channeled through the steel shell and that the lowest current density is in the soil just below the tank s center. However, because the electrodes are short, current flow is much more focused than for the long electrodes. Therefore, short electrodes yield higher current densities in localized regions, including the soil beneath the tank s center. This may be the reason why the 3D ERT tomographs show much larger resistivity changes than the long electrode tomographs.

The authors want to acknowledge the contributions of colleagues who provided valuable assistance in this work. Glendon Gee, and Brent Barnett (Pacific Northwest National Lab.) provided project management guidance, field resources and advice. Mark Sweeney (Pacific Northwest National Lab.) provided extensive field assistance and resources. Wes Bratton (Vista Engineering, Richland WA), provided data pertaining to the brine releases. This work was performed under the auspices of the U.S. Department of Energy by the University of California, Lawrence Livermore National Laboratory under Contract No. W7405-Eng-48. 


\section{Mock Tank Leak Test Facility at the 200 East Area}

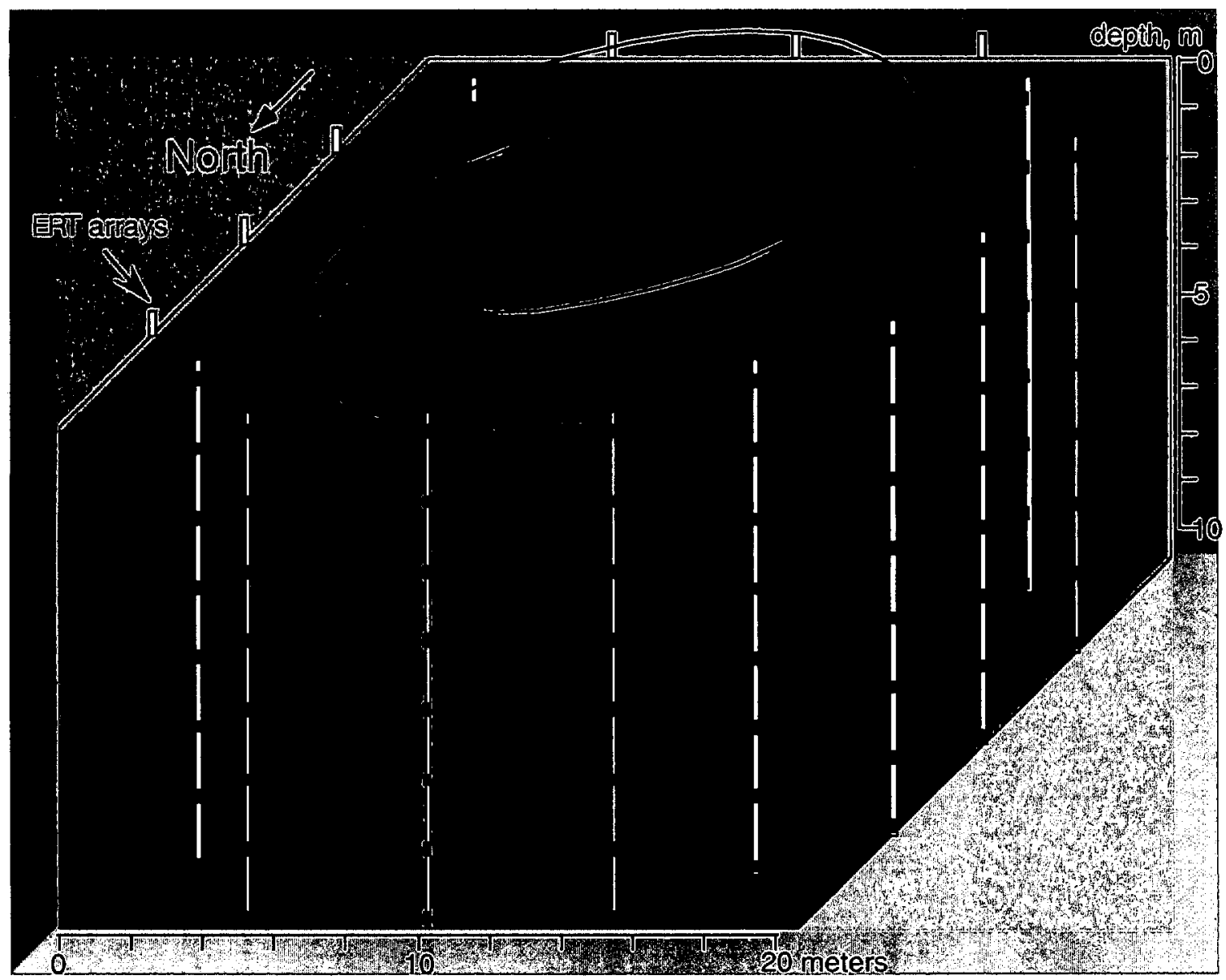

Figure 1. The point electrode model for the mock test site. The image shown is a 3D reconstruction of baseline conditions. 
Geometric Mean of Apparent Resistivity-Simple Leak Detection Approach

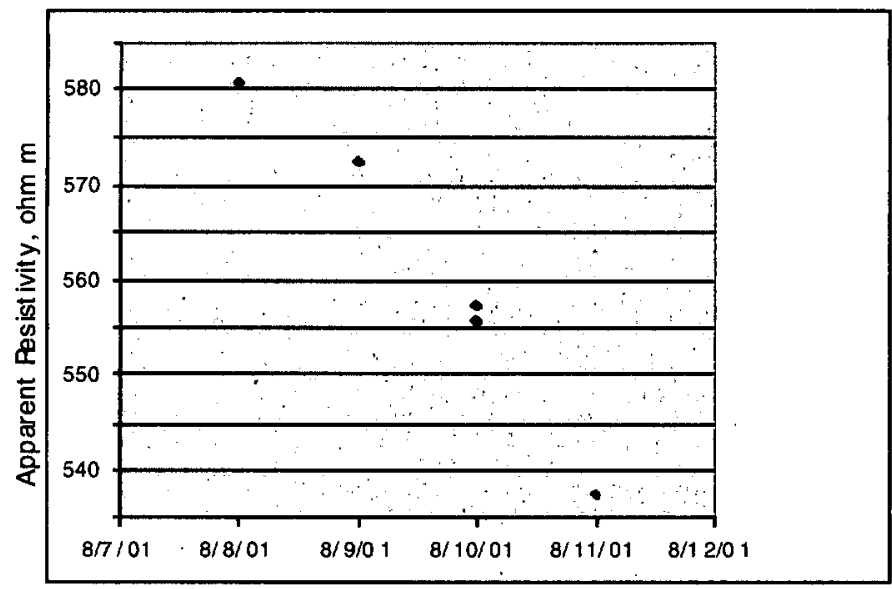

First Release

$8 / 8 / 01$ to $8 / 11 / 01$

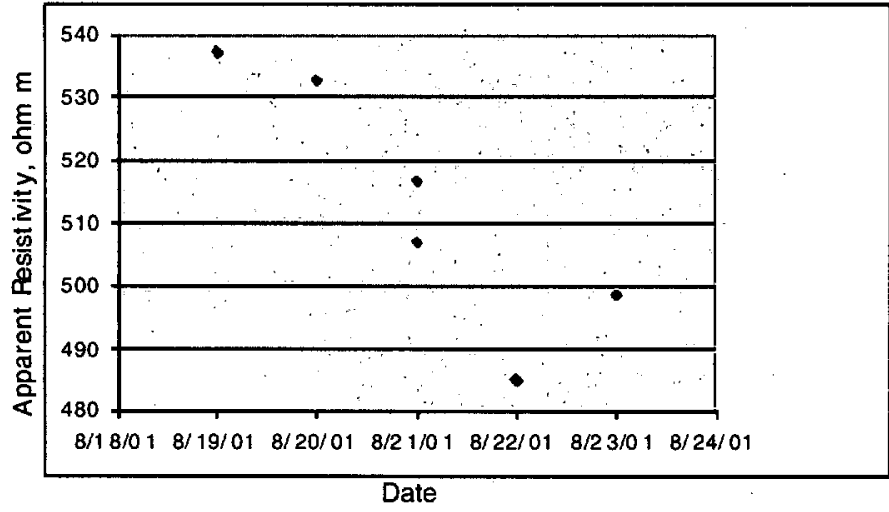

Two releases

$8 / 20 / 01$ AM to $8 / 21 / 01$

$8 / 21 / 01$ PM to $8 / 23 / 01$ AM

Figure 2. The figure shows the geometric mean of apparent resistivity beneath the Mock Tank during the two separate releases. 


\section{Hanford Tank Leak Test Facility at the 200 East Area}

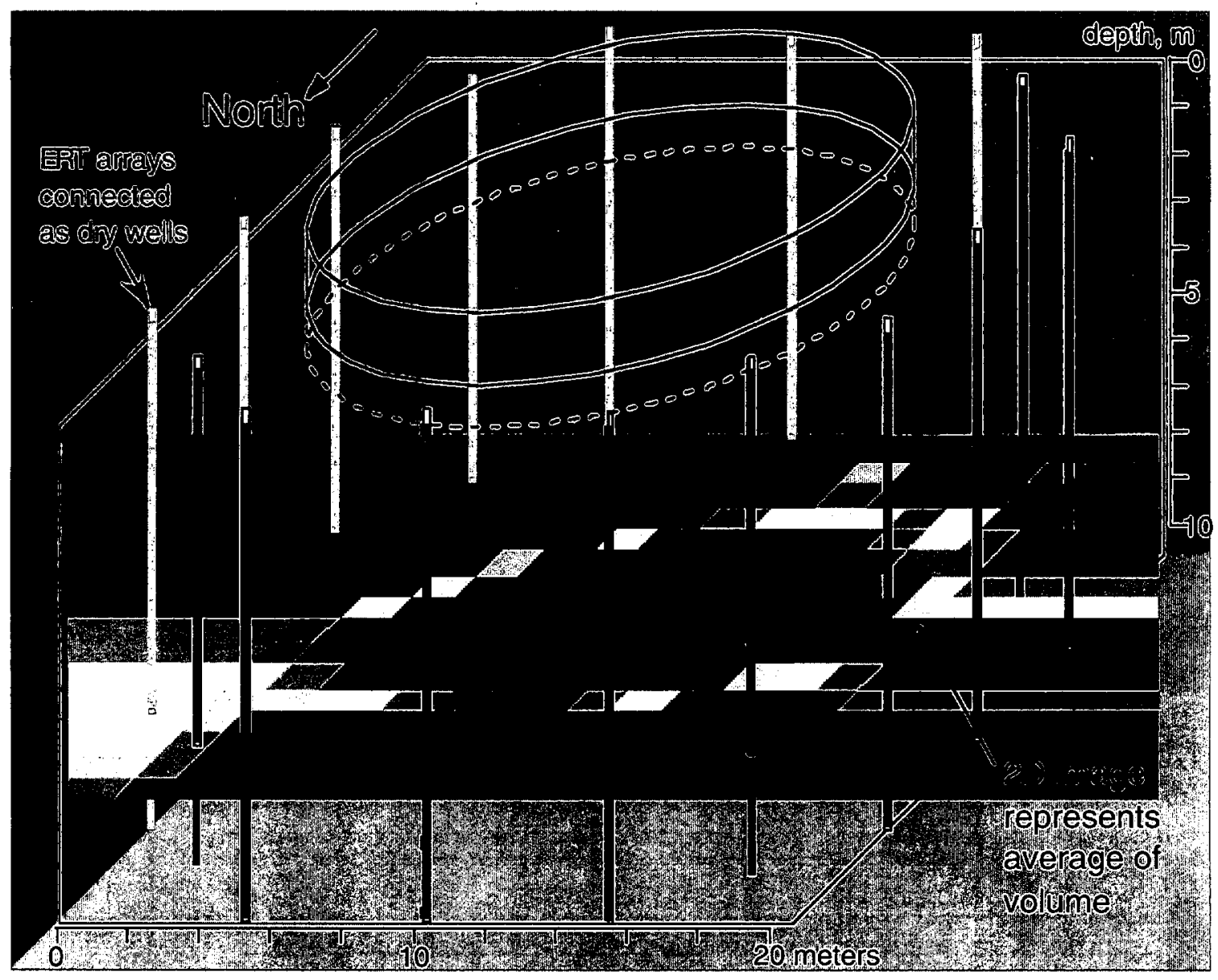

Figure 3. The dry well model for the mock tank test site. The image is shown as a plane but is actually an average of volumetric resistivity. 


\section{Dry well images}
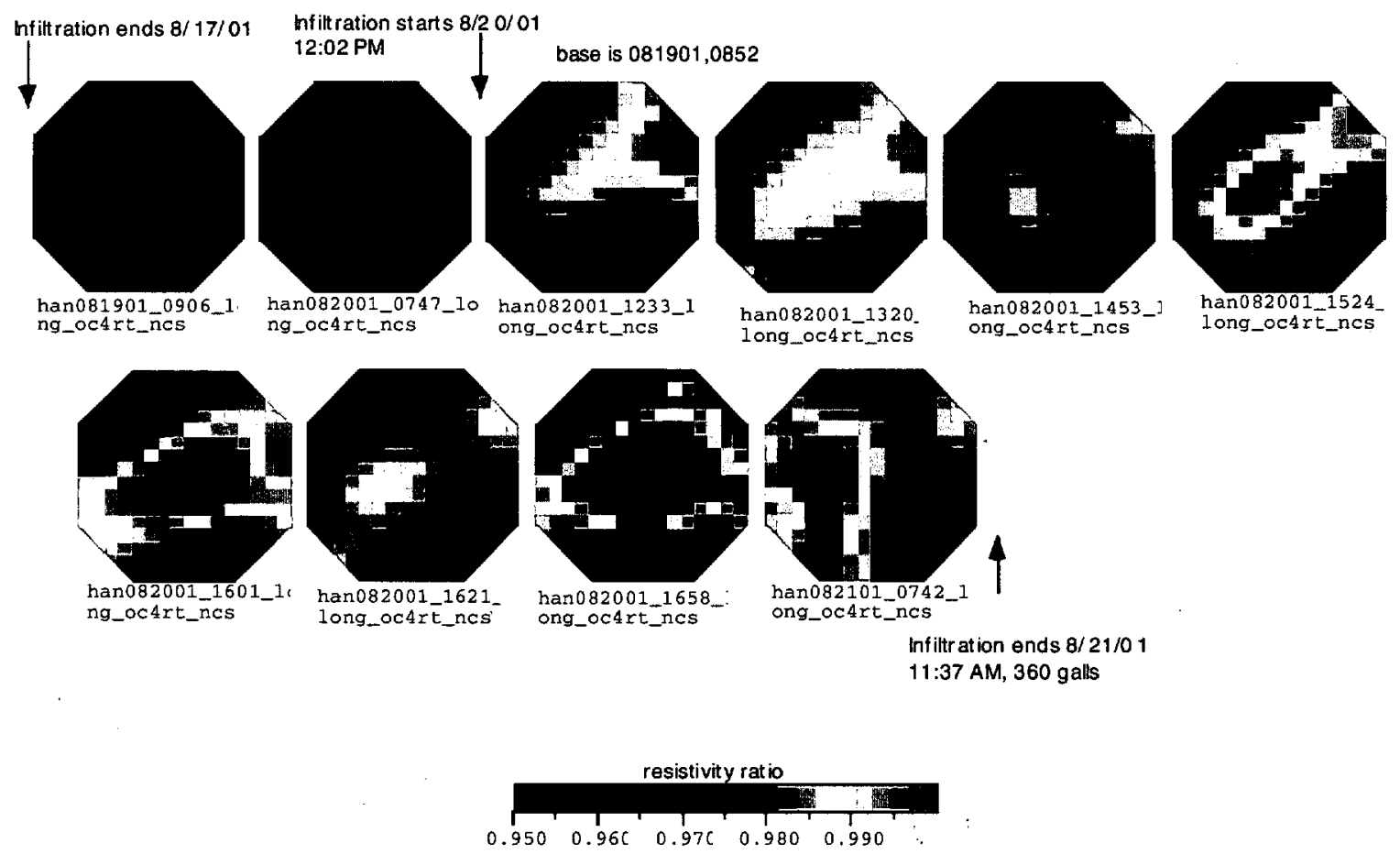

Figure 4. Sequence of $2 \mathrm{D}$ images using sixteen long electrodes during the final release. 
Baseline survey collected on 8/10/10 10:36 AM

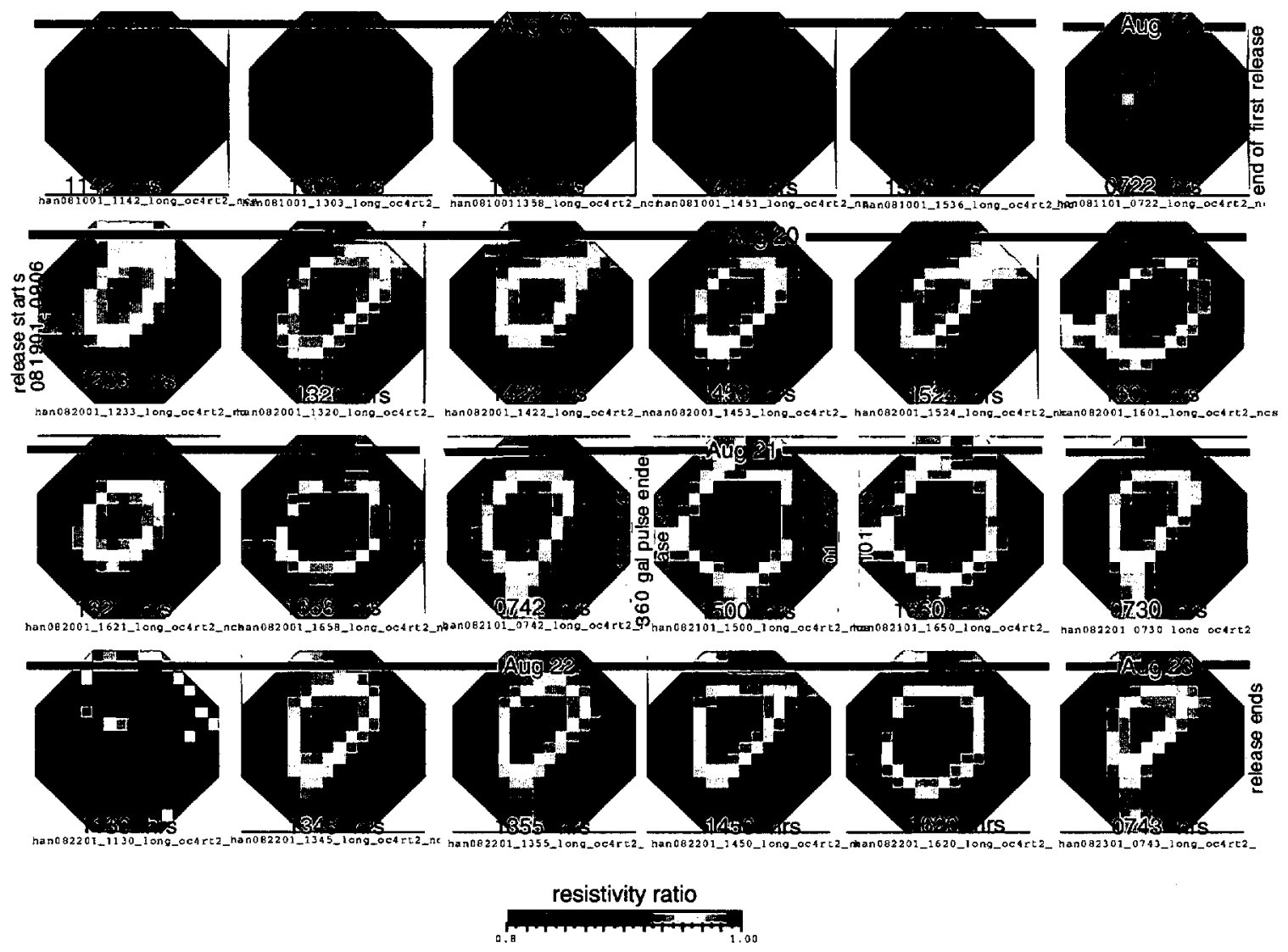

Figure 4a. Sequence of 2D images using sixteen long electrodes. All images calculated relative to a common baseline survey collected on 8/10/01, 10:36 AM.. 
Baseline survey collected on $8 / 10 / 10$ (10:36 AM
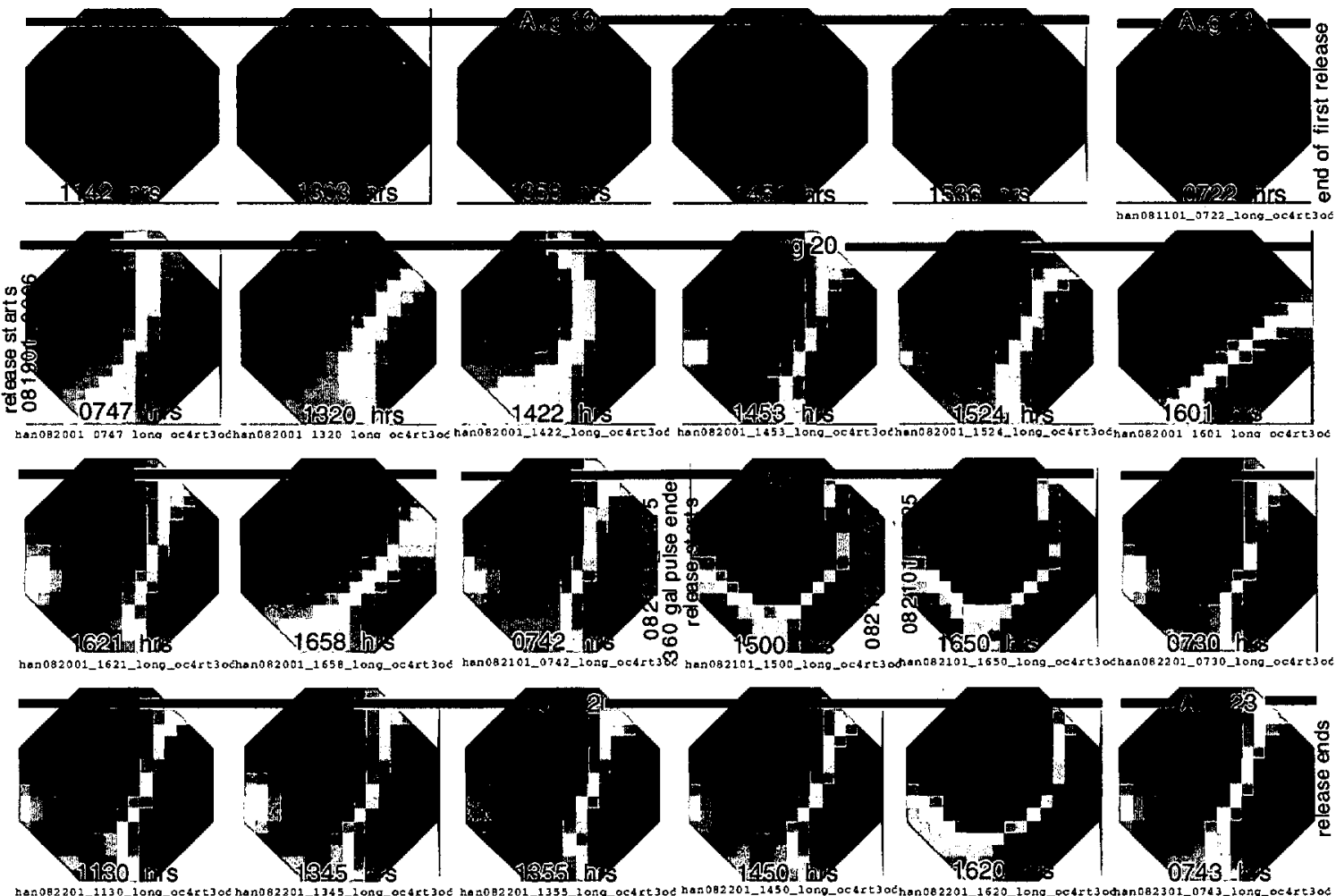

resistivity ratio

$0_{0.33}$

Figure $4 \mathrm{~b}$. Sequence of 2D images using only eight long electrodes. All images calculated relative to a common baseline survey collected on 8/10/01, 10:36 AM.. 


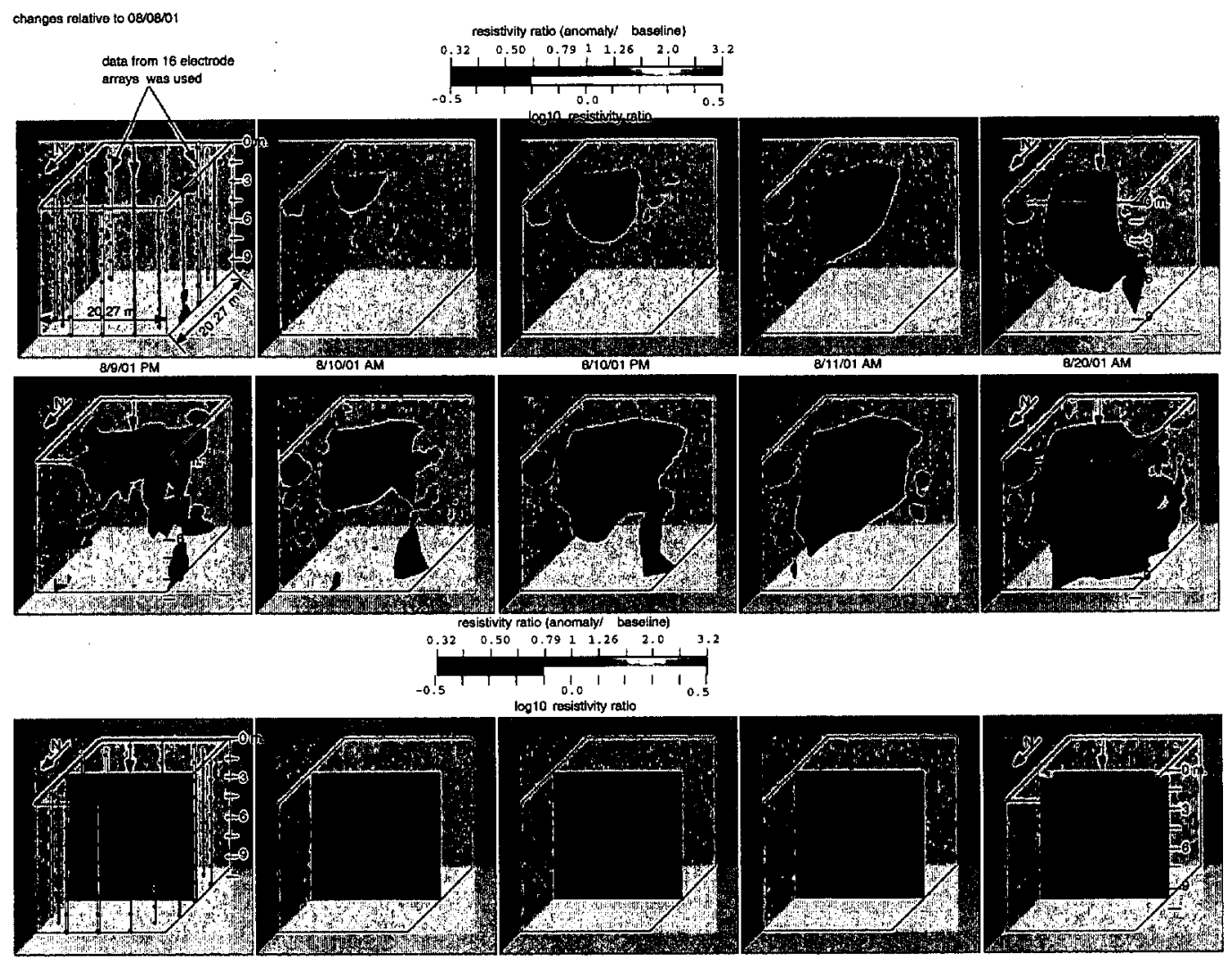

Figure 5. Three-dimensional ERT showing a history of the first three releases. . Sixteen electrode arrays were used to collect the data.The first row uses a transparency (sensitivity) threshold of 0.2 to depict changes in resistivity while the second row uses a threshold of 0.1 . The bottom row shows a single vertical section through the same $3 \mathrm{D}$ reconstruction 


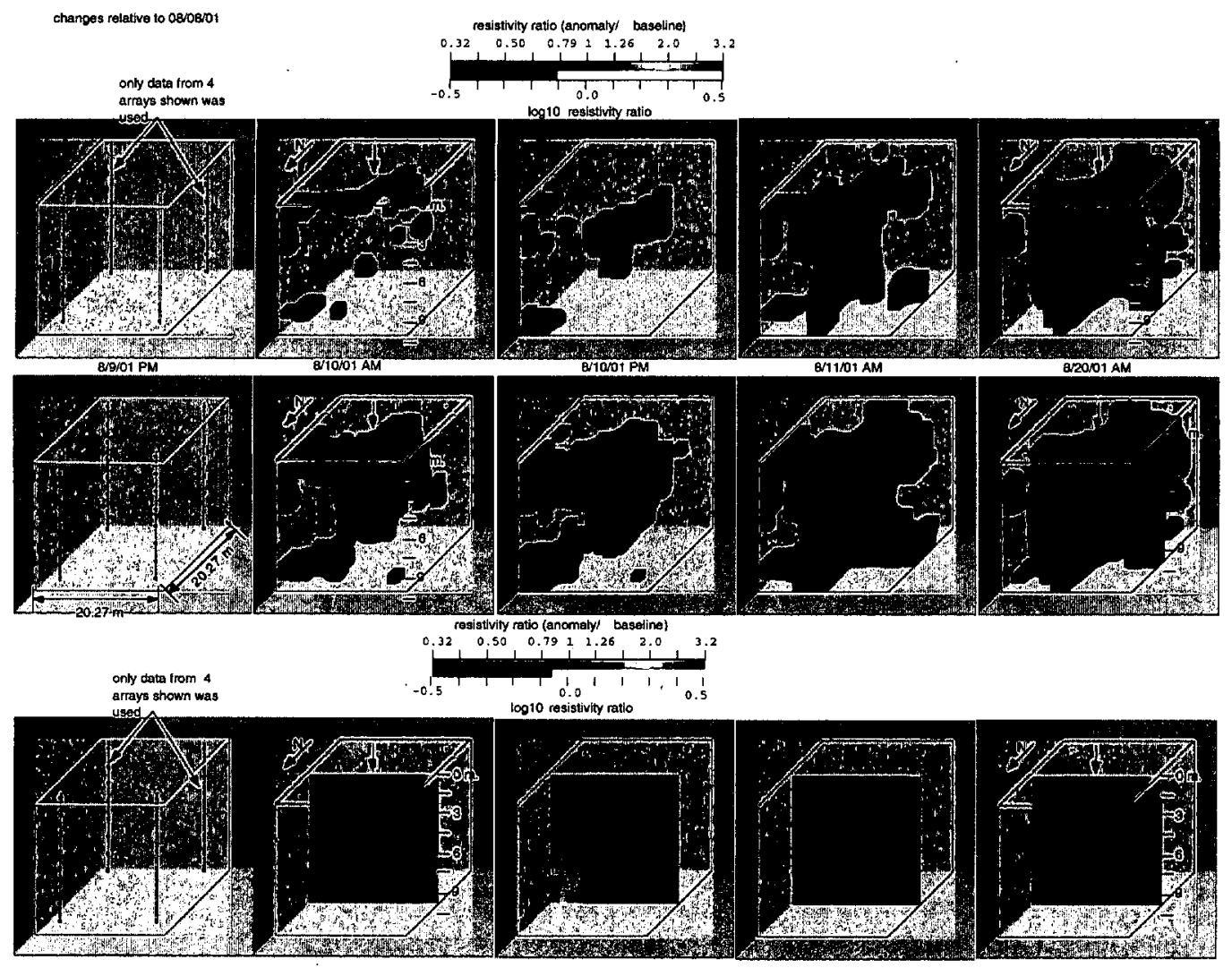

Figure 5a. Three-dimensional ERT showing a history of the first three releases. Only four electrode arrays were used to collect the data. The first row uses a transparency (sensitivity) threshold of 0.1 to depict changes in resistivity while the second row uses a threshold of 0.05 . The bottom row shows a single vertical section through the same $3 \mathrm{D}$ reconstruction. 
baseline $=08200$

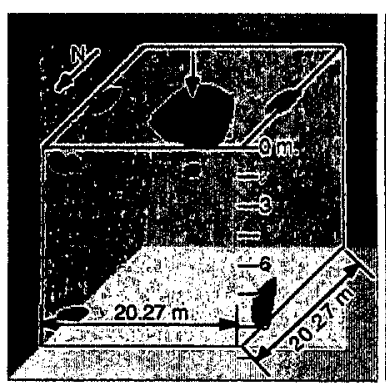

8/21/01 around 9 AM

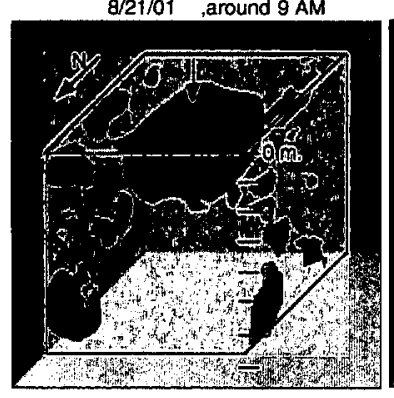

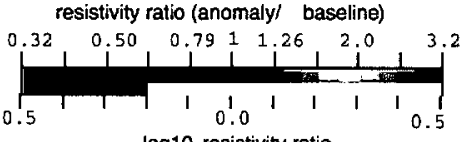

$\log 10$ resistivity ratio

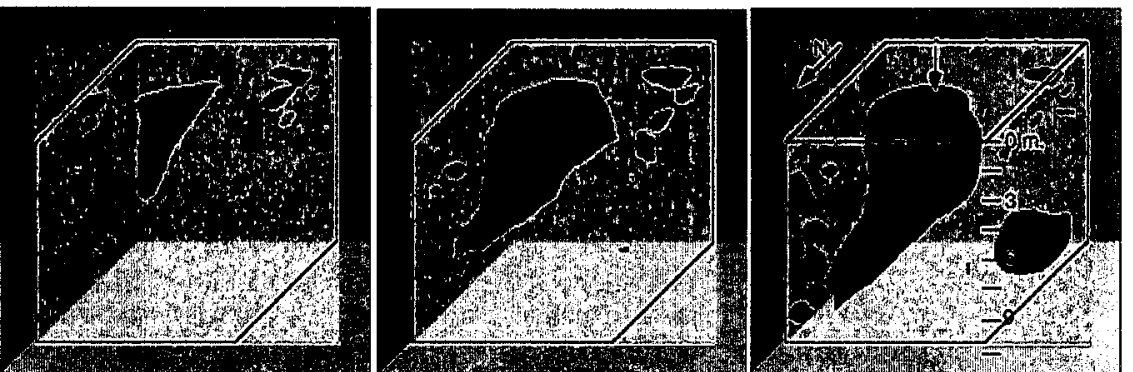

8/21/01, noon
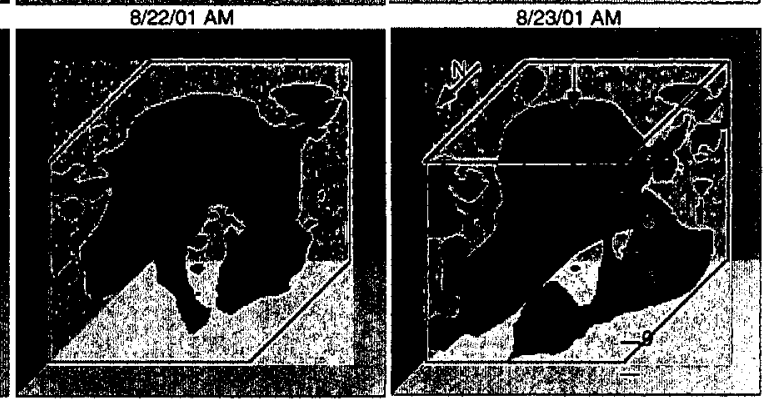

resistivity ratio (anomaly' baseline)

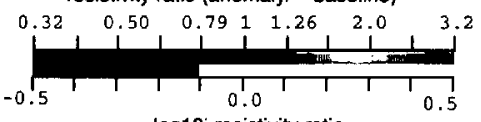

$\log 10$ resistivity ratio
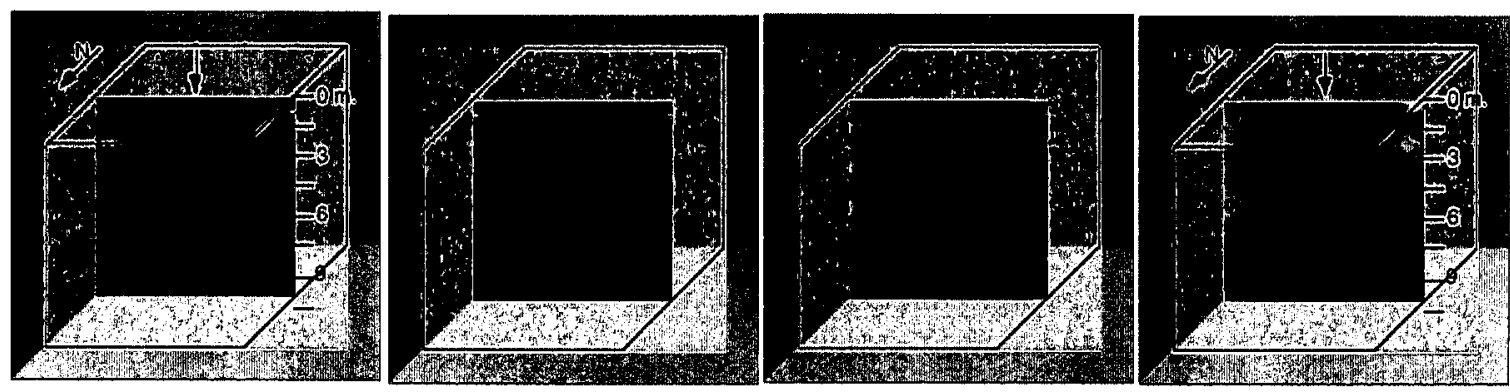

Figure 6. Three-dimensional ERT showing a history of the fifth release. The data was collected using 16 arrays of point electrodes. The format is the same as in Figure 5. 
$8 / 08 / 01$ prior to beginning of releases

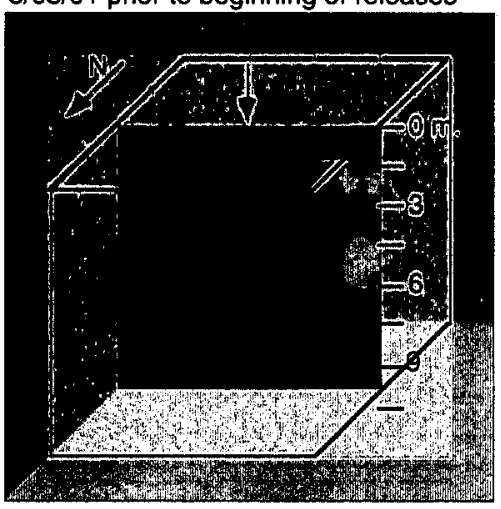

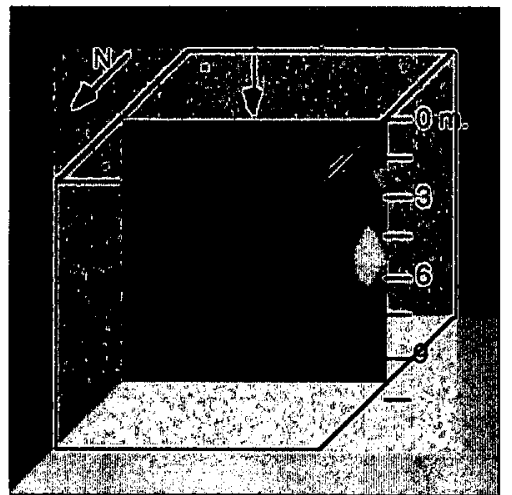

$8 / 11 / 01$

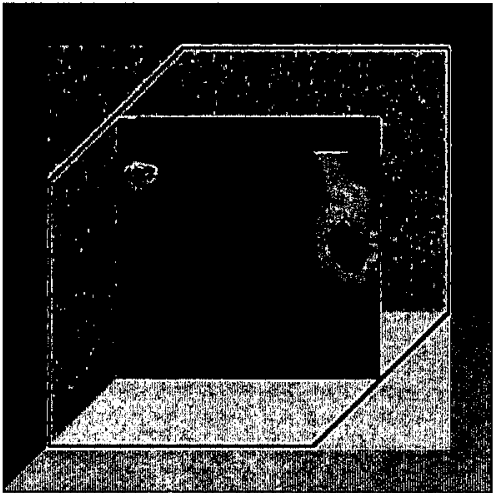

$8 / 19 / 01$

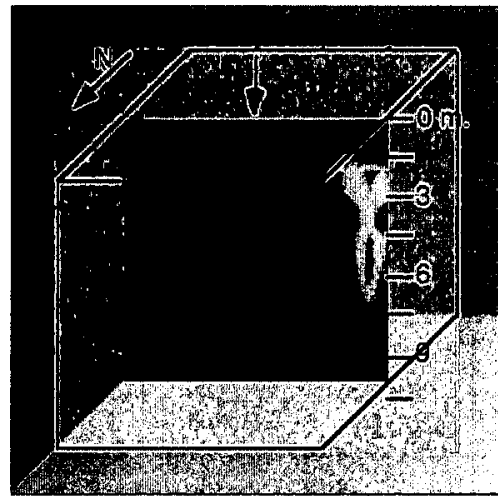

$8 / 23 / 01$

$\log 10$ resistivity ohm-m

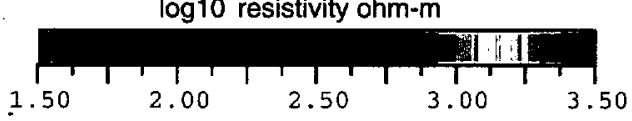

Figure 7. Three-dimensional ERT showing a history of all releases during the experiment. The data was collected using 16 arrays of point electrodes. These reconstructions are not of changes in resistivity but rather show the actual values of resistivity beneath the tank at selected times. Only a single slice through the $3 \mathrm{D}$ volume is shown here. 


\section{Long electrode (dry well) error analysis}

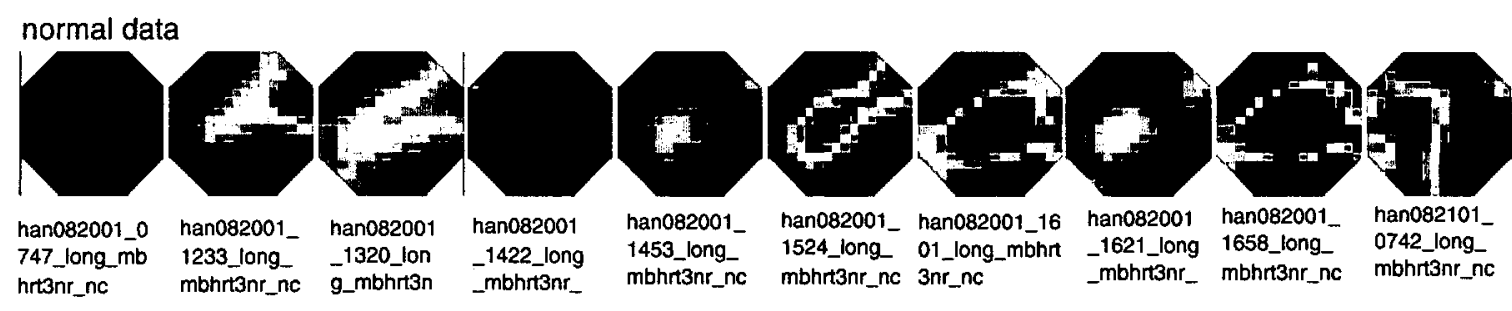

reciprocal data

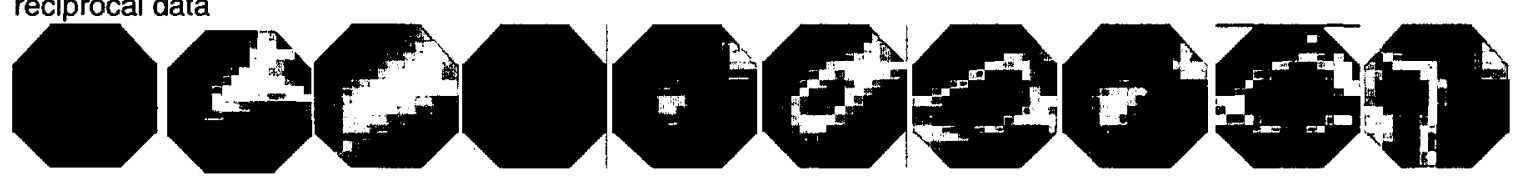

baseline is data collected on $8 / 19 / 01$

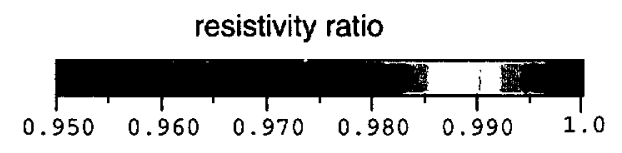

Figure 8. Error analysis for the long electrode ERT approach. The data was collected using 16 long electrodes. 


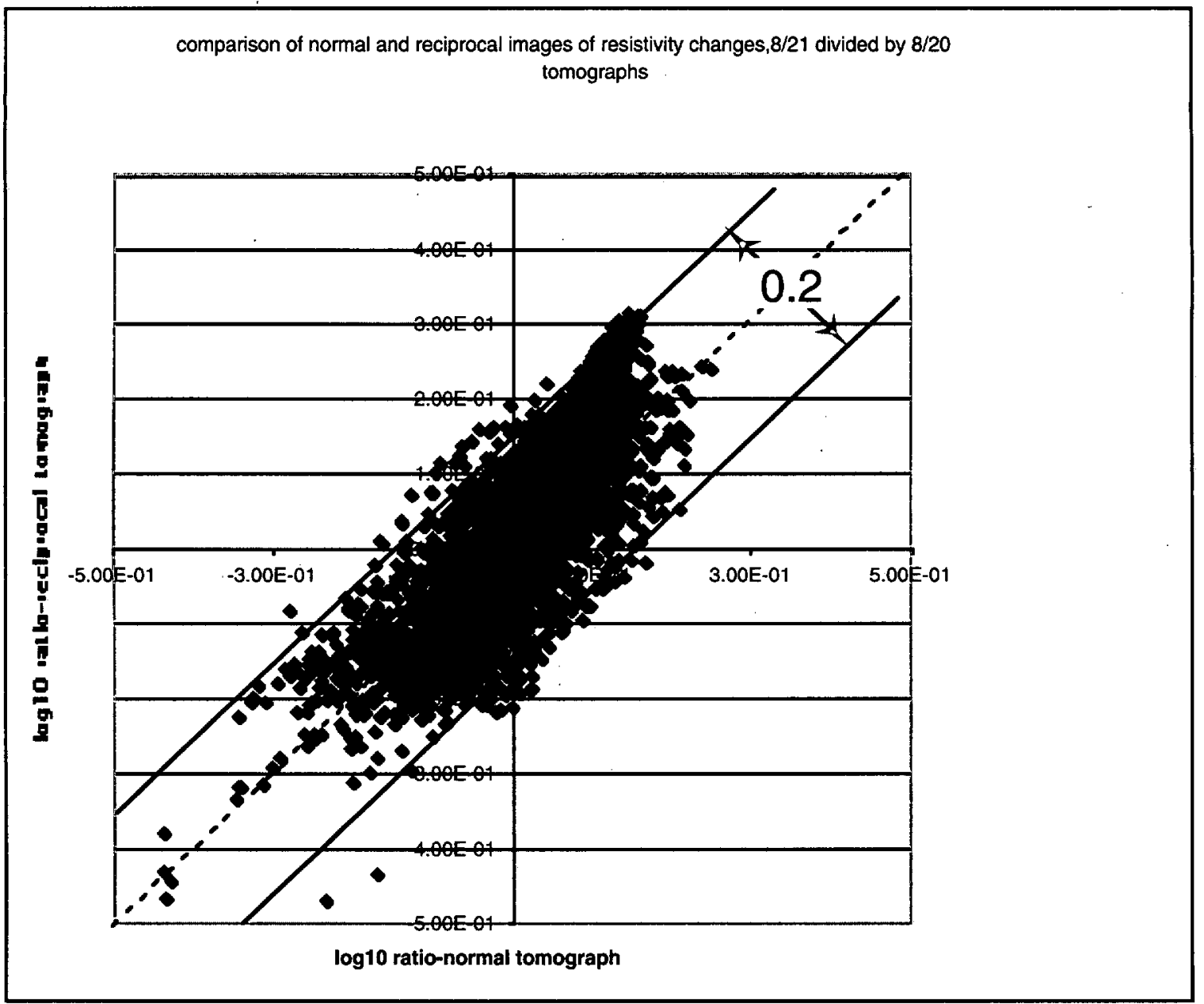

Figure 9. Error analysis for the 3D ERT reconstructions. Axes are the reconstructed ratios for the normal and reciprocal data. A reasonable error in the logarithm of the resistivity ratio is about $+/-0.1(0.2)$. 
Surface tank leak detection

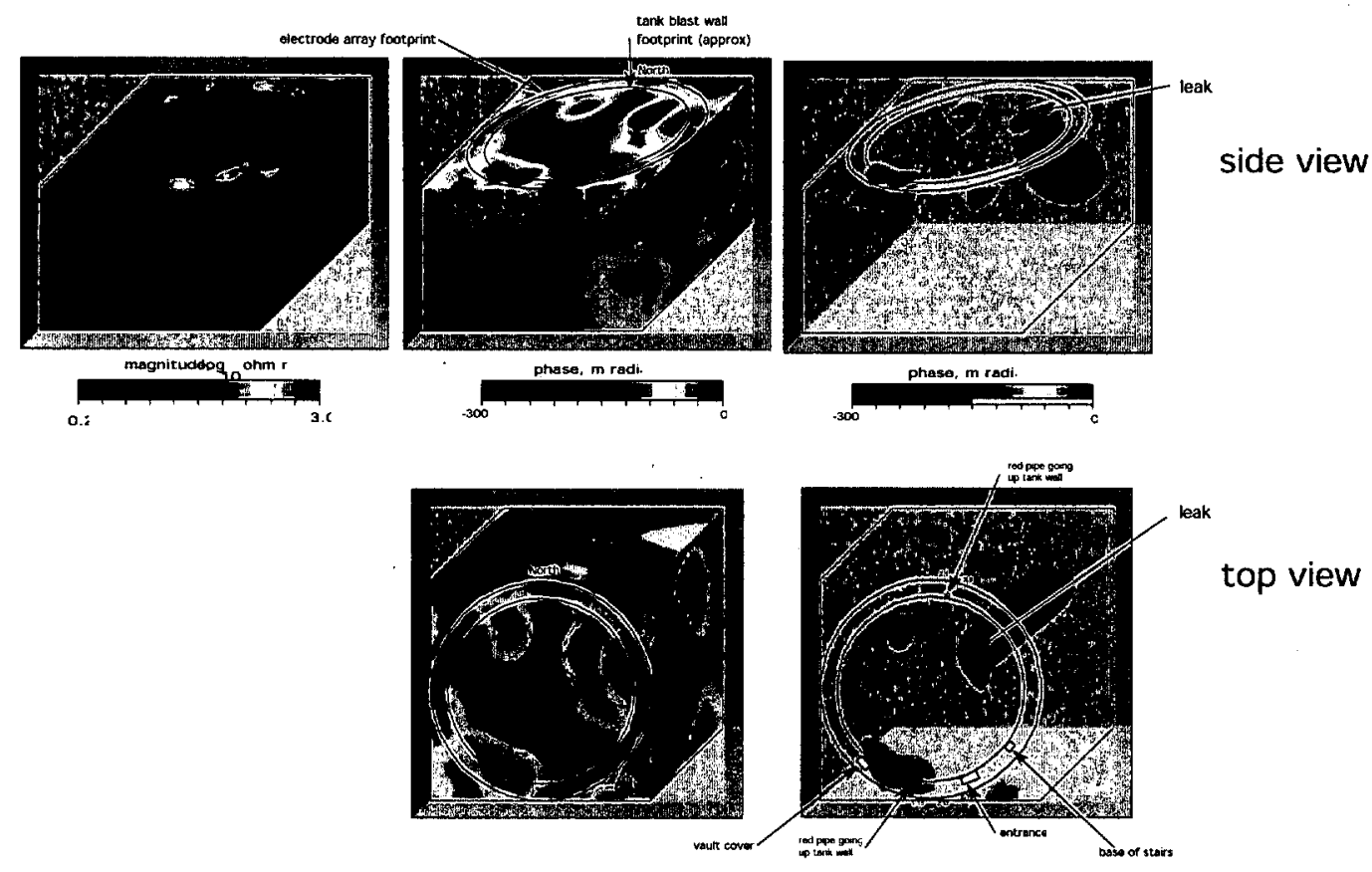

Figure 10. ERT image under a surface fuel storage tank using a ring of electrodes on the ground surface around the tank. 


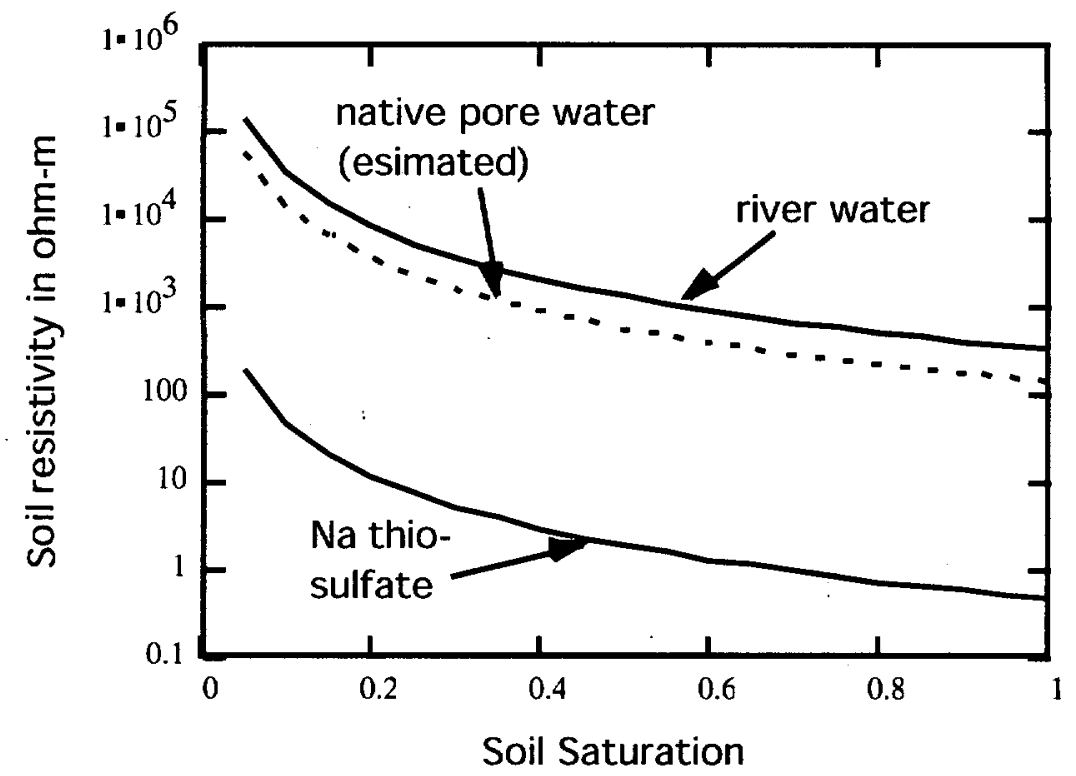

assumptions:

1) mimimal surface conductance

2) porosity $=0.3$

3) saturation exponent $=2.0$

4) cementation exponent $=1.3$

5) river water $=70 \mathrm{ohm}-\mathrm{m}$ (measured)

6) natural pore water $=30 \mathrm{ohm}-\mathrm{m}$ (assumed)

7) sodium thio-sulfate solution $=0.1 \mathrm{ohm}-\mathrm{m}$ (measured)

Figure A.1. Archie's equation for soil saturation and soil water resistivity expected at the mock tank site. 

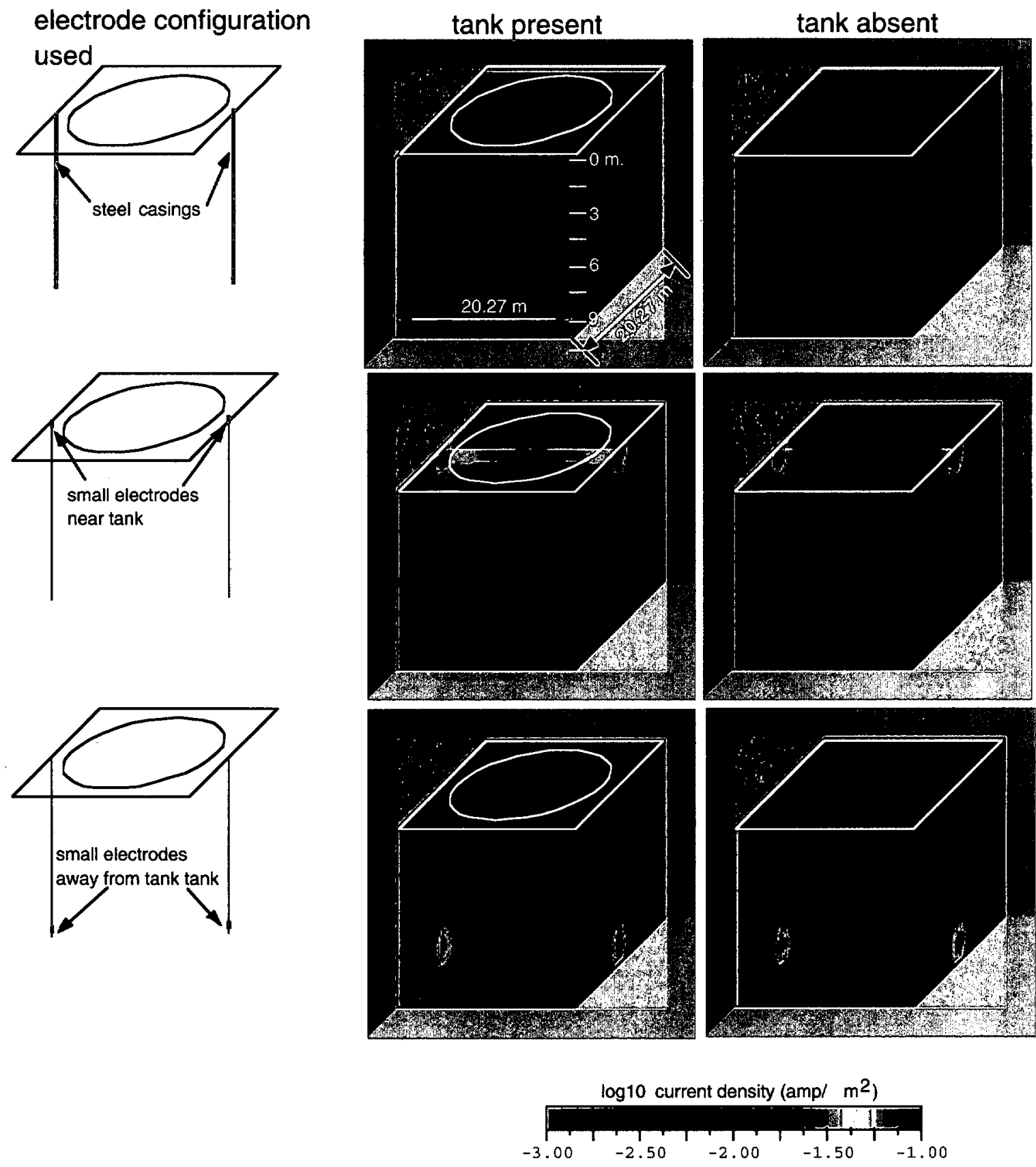

Figure B.1. Numerical modeling results showing the current densities associated with three different electrodes configuration. Scenarios with and without the tank are considered. Regions of high current density (shown in the warmer colors) indicate regions to which the measurements have the highest sensitivity. 